\title{
Structural, Mechanical, Imaging and in Vitro Evaluation of the Combined Effect of Gd3+ and Dy3+ in the ZrO2-SiO2 Binary System
}

DOI:

10.1021/acs.inorgchem.8b00337

\section{Document Version}

Accepted author manuscript

Link to publication record in Manchester Research Explorer

Citation for published version (APA):

Vasanthavel, S., Awasthi, S., Dhayalan, A., Derby, B., \& Kannan, S. (2018). Structural, Mechanical, Imaging and in Vitro Evaluation of the Combined Effect of Gd3+ and Dy3+ in the ZrO2-SiO2 Binary System. Inorganic Chemistry, 57(8), 4602-4612. https://doi.org/10.1021/acs.inorgchem.8b00337

\section{Published in:}

Inorganic Chemistry

\section{Citing this paper}

Please note that where the full-text provided on Manchester Research Explorer is the Author Accepted Manuscript or Proof version this may differ from the final Published version. If citing, it is advised that you check and use the publisher's definitive version.

\section{General rights}

Copyright and moral rights for the publications made accessible in the Research Explorer are retained by the authors and/or other copyright owners and it is a condition of accessing publications that users recognise and abide by the legal requirements associated with these rights.

\section{Takedown policy}

If you believe that this document breaches copyright please refer to the University of Manchester's Takedown Procedures [http://man.ac.uk/04Y6Bo] or contact uml.scholarlycommunications@manchester.ac.uk providing relevant details, so we can investigate your claim.

\section{OPEN ACCESS}


Structural, mechanical, imaging and in vitro evaluation of the combined effect of $\mathrm{Gd}^{3+}$ and $\mathrm{Dy}^{3+}$ in the $\mathrm{ZrO}_{2}-\mathrm{SiO}_{2}$ binary system

S. Vasanthavel ${ }^{\mathrm{a}, \mathrm{b}}$, Sharad Awasthi ${ }^{\mathrm{b}}$, Arunkumar Dhayalan $^{\mathrm{b}}$, Brian Derby $^{\mathrm{c}}$ and S. Kannan ${ }^{\mathrm{a}}$

${ }^{a}$ Centre for Nanoscience and Technology, Pondicherry University, Puducherry-605 014, INDIA

${ }^{b}$ Department of Biotechnology,

Pondicherry University, Puducherry-605 014, INDIA

${ }^{c}$ School of Materials, University of Manchester

Manchester, M13 9PL, UNITED KINGDOM

\section{Corresponding Author's Address}

Dr. S. Kannan

Centre for Nanoscience and Technology,

Pondicherry University, Puducherry-605014, INDIA

E-mail:para_kanna@yahoo.com

Phone: 0091-413-2654973 


\section{ABSTRACT}

Mechanical strength and biocompatibility are considered the main prerequisites for materials in total hip replacement (THR) or joint prosthesis. Non-invasive surgical procedures are necessary to monitor the performance of a medical device in vivo after implantation. To this aim, simultaneous $\mathrm{Gd}^{3+}$ and $\mathrm{Dy}^{3+}$ additions to the $\mathrm{ZrO}_{2}-\mathrm{SiO}_{2}$ binary system have been investigated. The results demonstrate the effective role of $\mathrm{Gd}^{3+}$ and $\mathrm{Dy}^{3+}$ to maintain the structural and mechanical stability of cubic zirconia $\left(c-\mathrm{ZrO}_{2}\right)$ up to $1400{ }^{\circ} \mathrm{C}$, through their occupancy of $\mathrm{ZrO}_{2}$ lattice sites. A gradual tetragonal to cubic zirconia $\left(t-\mathrm{ZrO}_{2} \rightarrow c-\mathrm{ZrO}_{2}\right)$ phase transition is also observed that is dependent on the $\mathrm{Gd}^{3+}$ and $\mathrm{Dy}^{3+}$ content in the $\mathrm{ZrO}_{2}-\mathrm{SiO}_{2}$. The crystallization of either $\mathrm{ZrSiO}_{4}$ or $\mathrm{SiO}_{2}$ at elevated temperatures is delayed by the enhanced thermal energy consumed by the excess inclusion of $\mathrm{Gd}^{3+}$ and $\mathrm{Dy}^{3+}$ at $c-\mathrm{ZrO}_{2}$ lattice. The addition of $\mathrm{Gd}^{3+}$ and $\mathrm{Dy}^{3+}$ leads to an increase in the density, elastic modulus, hardness, and toughness above that of unmodified $\mathrm{ZrO}_{2}-\mathrm{SiO}_{2}$. The multi-modal imaging contrast enhancement of the $\mathrm{Gd}^{3+}$ and $\mathrm{Dy}^{3+}$ combinations were revealed through MRI and CT contrast imaging tests. Biocompatibility of the $\mathrm{Gd}^{3+}$ and $\mathrm{Dy}^{3+}$ dual doped $\mathrm{ZrO}_{2}-\mathrm{SiO}_{2}$ systems was verified through in vitro biological studies.

Key words: $\mathrm{ZrO}_{2}-\mathrm{SiO}_{2}$; Gadolinium; Dysprosium; Co-substitution; Structure; Properties. 


\section{INTRODUCTION}

The $\mathrm{ZrO}_{2}-\mathrm{SiO}_{2}$ binary oxide system has been proposed as a new class of synthetic substitute material suitable for hard tissue replacements because of its appropriate mechanical strength and biocompatibility. ${ }^{1}$ The rationale for choosing this specific combination is based on the following reasoning. $\mathrm{ZrO}_{2}$ is a well-established bio-inert ceramic that has many years of commercial application because of its superior mechanical properties. However, the failure of $\mathrm{ZrO}_{2}$ implants caused by the slow degradation of the toughening tetragonal zirconia $\left(t-\mathrm{ZrO}_{2}\right)$ phase to monoclinic zirconia $\left(m-\mathrm{ZrO}_{2}\right)$ in vivo after implantation has been reported. ${ }^{2} \mathrm{SiO}_{2}$ as one of the prime component in bioactive glasses has been known to elicit a biocompatible response that promotes host-implant interaction by forming a hydroxyl carbonate apatite layer during in vivo exposure. ${ }^{3}$ $\mathrm{SiO}_{2}$ is also employed to stabilize $t-\mathrm{ZrO}_{2}$, in preference to the other two polymorphs namely $m$ $\mathrm{ZrO}_{2}$ and cubic $\left(c-\mathrm{ZrO}_{2}\right){ }^{4}$ It has also been reported that the presence of $\mathrm{SiO}_{2}$ as an amorphous matrix in $\mathrm{ZrO}_{2}-\mathrm{SiO}_{2}$ systems may help prevent the unwanted $t-\rightarrow m-\mathrm{ZrO}_{2}$ transition during accelerated leach tests. ${ }^{5}$ Nevertheless, the partial transformation of $t-\rightarrow m-\mathrm{ZrO}_{2}$ in the $\mathrm{ZrO}_{2}-\mathrm{SiO}_{2}$ system beyond $1100{ }^{\circ} \mathrm{C}$ limits the densification of sintered specimens and leads to mechanical properties inferior to yttria stabilized $t-\mathrm{ZrO}_{2}$ polycrystals (Y-TZP).

There is an interest in developing biomaterials for bone implant applications that can be monitored non-invasively in vivo through advanced imaging methods, while retaining adequate levels of mechanical strength and biocompatibility. This has led to large numbers of studies that have reported on the introduction of rare earth oxides into biomaterials.$^{6-9}$ Moreover, the ability of rare earth metal oxides to stabilise the $t-\mathrm{ZrO}_{2}$ polymorph at high temperatures might improve the sinterability of the $\mathrm{ZrO}_{2}-\mathrm{SiO}_{2}$ system. This has been investigated in previous works by the authors in which the influence of individual additions of $\mathrm{La}^{3+}(\mathrm{LZS}), \mathrm{Gd}^{3+}(\mathrm{GZS}), \mathrm{Dy}^{3+}(\mathrm{DZS})$ and $\mathrm{Ce}^{4+}$ (CZS) to the $\mathrm{ZrO}_{2}-\mathrm{SiO}_{2}$ system have been reported. ${ }^{10-13} \mathrm{La}^{3+}$ additions stabilizes the $t-\mathrm{ZrO}_{2}$ 
polymorph up to $1000{ }^{\circ} \mathrm{C}$, whereas $\mathrm{Gd}^{3+}$ induces a phase transition from $t-\rightarrow c-\mathrm{ZrO}_{2}$ that is dependent on $\mathrm{Gd}^{3+}$ content and moreover the structural stability of $c-\mathrm{ZrO}_{2}$ is retained beyond 1100 ${ }^{\circ} \mathrm{C}$. The addition of $\mathrm{Ce}^{4+}$ up to a certain concentration preserves $t-\mathrm{ZrO}_{2}$ to $1300{ }^{\circ} \mathrm{C}$ by occupying the lattice sites of $\mathrm{ZrO}_{2}$, while its further addition yields $c-\mathrm{CeO}_{2}$ alongside $t-\mathrm{ZrO}_{2}{ }^{12}$ In contrast, $\mathrm{Dy}^{3+}$ additions stabilizes $t-\mathrm{ZrO}_{2}$ to $1400{ }^{\circ} \mathrm{C}$ with additions up to $50 \mathrm{wt}$. $\%$ concentration without formation of additional phases. ${ }^{13}$

The current study investigates the simultaneous addition of both $\mathrm{Gd}^{3+}$ and $\mathrm{Dy}^{3+}$ to the $\mathrm{ZrO}_{2}-\mathrm{SiO}_{2}$ system using an in-situ sol-gel synthesis method. Among the lanthanides, $\mathrm{Gd}^{3+}$ based complexes are commercially employed as positive $\left(\mathrm{T}_{1}\right)$ MRI contrast agents owing to the unique magnetic properties conferred by its seven unpaired $4 f$ electrons. ${ }^{14}$ Dy $^{3+}$, with a high magnetic moment of 10.2 $\mu \mathrm{B}$ and asymmetric electronic ground state of ${ }^{6} \mathrm{H}_{15 / 2}$, enunciates enhanced transverse relaxivity at high magnetic fields, which makes them suitable for use as negative $\left(T_{2}\right)$ MRI contrast agents. ${ }^{15}$ The contrast nature of $\mathrm{Dy}^{3+}$ doped $\mathrm{ZrO}_{2}-\mathrm{SiO}_{2}$ system has been previously reported by the authors. ${ }^{13}$ Furthermore, the high atomic number and K-edge energy values of $\mathrm{Z}=66$ and 53.8 $\mathrm{keV}$ respective of $\mathrm{Dy}^{3+}$ ensures a high X-ray attenuation coefficient of $3.36 \mathrm{~cm}^{2} \cdot \mathrm{g}^{-1}$ at $100 \mathrm{keV}$ and hence it is also employed as a X-Ray computed tomography (CT) contrast agent. ${ }^{16}$ Thus this study explores the simultaneous additions of $\mathrm{Gd}^{3+}$ and $\mathrm{Dy}^{3+}$ to the $\mathrm{ZrO}_{2}-\mathrm{SiO}_{2}$ system followed by a systematic characterisation of the structural behaviour, resulting mechanical properties and multi-modal imaging features.

\section{MATERIALS AND METHODS}

\subsection{Powder synthesis}

The sol-gel technique was used to prepare $\mathrm{Gd}^{3+}$ and $\mathrm{Dy}^{3+}$ doped $\mathrm{ZrO}_{2}-\mathrm{SiO}_{2}(\mathrm{GDZS})$ binary oxides. Pure $\mathrm{ZrO}_{2}-\mathrm{SiO}_{2}(\mathrm{PZS})$ without any additions of $\mathrm{Gd}^{3+}$ and $\mathrm{Dy}^{3+}$ content was also prepared by using the same technique for comparative purposes. The precursors used for the synthesis were 
$\mathrm{Gd}\left(\mathrm{NO}_{3}\right)_{3}, \mathrm{Dy}\left(\mathrm{NO}_{3}\right)_{3}, \mathrm{ZrOCl}_{2}$ and $\left(\mathrm{C}_{2} \mathrm{H}_{5} \mathrm{O}\right)_{4} \mathrm{Si}$, purchased from Sigma-Aldrich, Bangalore, India. An equal molar ratio of $\mathrm{ZrOCl}_{2}$ and $\left(\mathrm{C}_{2} \mathrm{H}_{5}\right)_{4} \mathrm{OSi}$ was maintained for all the synthesis whereas varied molar concentrations of $\mathrm{Gd}\left(\mathrm{NO}_{3}\right)_{3}$ and $\mathrm{Dy}\left(\mathrm{NO}_{3}\right)_{3}$ were added with respect to the concentrations of $\mathrm{ZrOCl}_{2}$ and $\left(\mathrm{C}_{2} \mathrm{H}_{5} \mathrm{O}\right)_{4} \mathrm{Si}$. Table 1 presents the concentrations of the compositions synthesized and their respective sample codes.

The synthetic procedure is briefly explained as follows. Initially $\left(\mathrm{C}_{2} \mathrm{H}_{5}\right)_{4} \mathrm{OSi}$ was added to the required amount of ethanol and stirred vigorously at room temperature. Separately prepared individual stock solutions of $\mathrm{Gd}\left(\mathrm{NO}_{3}\right)_{3}, \mathrm{Dy}\left(\mathrm{NO}_{3}\right)_{3}$ and $\mathrm{ZrOCl}_{2}$ were added to this mixture and stirred at $80{ }^{\circ} \mathrm{C}$ for 30 minutes; then, $0.1 \mathrm{M}$ of $\mathrm{HNO}_{3}$ was added as a catalyst. The resultant homogeneous solution was stirred to yield a wet gel and dried at $120^{\circ} \mathrm{C}$ for 24 hours to remove the excess water content. The dried gel was ground to a fine powder and subsequently characterized.

\subsection{Powder characterization}

The synthesized powders were heat treated at different temperatures in a muffle furnace for 4 hours and their phase behaviour was analysed by X-ray diffraction (XRD) (Ultima IV, Rigaku, Tokyo, Japan) with $\mathrm{Cu} \mathrm{K \alpha}$ radiation $(\lambda=0.15406 \mathrm{~nm})$ produced at $40 \mathrm{kV}$ and $30 \mathrm{~mA}$, scanning the diffraction angles $(2 \theta)$ between 10 and $70^{\circ}$ with a step size of $0.02^{\circ}$ at $2 \theta \mathrm{s}^{-1}$. Phases were identified using Standard ICDD (International Centre for Diffraction Data) Card Nos. 01-0830944 for $m-\mathrm{ZrO}_{2}, 01-078-1765$ for $t-\mathrm{ZrO}_{2}, 01-071-4810$ for $c-\mathrm{ZrO}_{2}, 01-083-1378$ for $\mathrm{ZrSiO}_{4}$ and 00-039-1425 for cristobalite $\left(c-\mathrm{SiO}_{2}\right)$. The vibrational modes of the functional groups in the powders were evaluated using Raman spectra recorded from a Confocal Raman microscope (inVia Raman microscope, Renishaw, Wootton-under-Edge, UK). Vibrating sample magnetometer (VSM 7404 Series, Lake Shore Cryotronics, Westerville, OH, USA) was utilized to analyse the magnetic behaviour of the powders through magnetic hysteresis measurements at 
ambient temperature with a maximum applied magnetic field of $15 \mathrm{kGauss}$ that varied from -10 kOe to $10 \mathrm{kOe}$. Morphological features and selected area electron diffraction (SAED) patterns were recorded using Transmission Electron Microscopy (TEM) and Scanning Transmission Electron Microscopy (STEM) using a Tecnai F30, 300 kV, field emission gun (FEG) microscope (FEI, Eindhoven, Netherlands) equipped with a high angle annular dark field detector for STEM imaging and a silicon drift detector for energy dispersive X-ray spectroscopy (EDX) analysis (Oxford Instruments, High Wycombe, UK). Rietveld method was used for the quantitative phase estimation of the recorded XRD patterns using GSAS-EXPGUI software package. ${ }^{17}$ For this purpose, standard Crystallographic Information Files (CIF) corresponding to the recorded phases such as $m-\mathrm{ZrO}_{2}, t-\mathrm{ZrO}_{2}, c-\mathrm{ZrO}_{2}, \mathrm{ZrSiO}_{4}$ and $c-\mathrm{SiO}_{2}$ were obtained from Smith et.al., ${ }^{18}$ Howard et.al., ${ }^{19}$ Wyckoff, ${ }^{20}$ Hazen et.al., ${ }^{21}$ and Dera et al., ${ }^{22}$ (American Mineralogist crystal structure database) respectively. The protocol for the structure refinement was performed in accordance with the authors' previous report. ${ }^{1}$

\subsection{Mechanical evaluation}

The hardness and elastic modulus of the PZS and GDZS samples were determined at room temperature by nanoindentation using a CETR Apex indenter (Bruker, Billerica, USA). For this purpose, the volatile impurities of the as-dried powders were removed by calcining at $700{ }^{\circ} \mathrm{C}$ and then milled for 2 hours in a planetary ball mill (Retsch, Haan, Germany). The resultant powders were pressed into circular pellets with $13 \mathrm{~mm}$ diameter and $1 \mathrm{~mm}$ thickness using a semiautomatic hydraulic press machine (Kimaya Engineers, Thane, India) under an applied load of 10 $\mathrm{kN}$ for $60 \mathrm{~s}$. The resulting pellets were heat treated at specific temperatures for 4 hours followed by diamond polishing prior to mechanical testing. The pellets were analysed for their surface

morphological features prior to diamond polishing using FE-SEM (Quanta ${ }^{\mathrm{TM}}$ FE 250, FEI), Nanoindentation was performed using a Berkovich indenter tip with a radius of $50 \mathrm{~nm}$ at an applied load of $100 \mathrm{mN}$. A conventional depth-sensing procedure was carried out to acquire 
mechanical data with a cycle consisting of a loading segment, dwell time at maximum load and an unloading segment. Data was analysed in accordance with the procedures described in ISO 14577. ${ }^{23}$ A single indent mode with 10 indents per pellet at random locations was systematically performed for all the pellets. Density measurements were carried out using Archimedes method and fracture toughness tests were performed using micro-indentation (microtest, MTR3/50-50/NI, Madrid, Spain). Indentation was performed at five different locations on the specimen surface with an applied load of $40 \mathrm{~N}$ using a Vickers indenter tip. Fracture toughness was calculated using the following relation as given below. ${ }^{24,25}$

$$
K_{I C}=0.0824\left(P / c^{3 / 2}\right)
$$

where $K_{I C}$ is the fracture toughness, $P$ is the applied load and $c$ is the indentation induced crack length.

\subsection{In vitro MR imaging}

Siemens Magnetom Avanto 1.5 Tesla MRI scanner was used to determine the $\mathrm{T}_{1}$ and $\mathrm{T}_{2}$ relaxivity of the GDZS-50 sample. The relaxivity values were quantified from the in vitro phantom images obtained from GDZS-50 at different $\mathrm{Gd}^{3+}$ and $\mathrm{Dy}^{3+}$ concentrations. Matlab, (The Mathworks Inc., MA, USA) software was used to calculate the relaxation rate maps by fitting all the corresponding curves. $T_{1}$ mapping was obtained by setting the following parameters: a fast spin echo (FSE) sequence with an echo train length $=16$, repetition time $(\mathrm{TR})=3000 \mathrm{~ms}$, matrix size $=512 \times 512$, slice thickness $=5 \mathrm{~mm}$, and number of slices $=1$. Similarly T2 mapping was carried out using the following parameters: echo time $(\mathrm{TE})=22$ to $352 \mathrm{~ms}$ (difference $=22 \mathrm{~ms}$ ) and images $=16$. The resultant images were used to determine the $\mathrm{T}_{1}$ and $\mathrm{T}_{2}$ relaxation times. 


\subsection{In vitro $\mathrm{CT}$ imaging}

To analyse CT contrast effectiveness, various concentrations of GDZS-50 samples $(0,1.25,2.5$, $5,10 \mathrm{mg} / \mathrm{mL}$ ) were evenly dispersed in aqueous solution in $5 \mathrm{~mL}$ tubes and images were acquired using a multislice spiral CT system (GE HISPEED CT/e, GE Healthcare, Chicago, IL, USA). Imaging parameters were set as follows: thickness of $0.9 \mathrm{~mm}$ at $120 \mathrm{KVp}$ and160 mA, Field of view (FOV) of $54.07 \mathrm{~mm} 9146.00 \mathrm{~mm}$ and an exposure time of $800 \mathrm{~ms} /$ rotation. Kodak Molecular Imaging Software (Eastman KODAK Company, Rochester, NY, USA) was used for the analysis of Phantom CT images and the GE HISPEED CT software was used to measure the Hounsfield Unit (HU) values.

\subsection{In vitro cellular studies}

The methodology of MTT assay, live/dead cell analysis, ALP activity tests and RT-PCR are presented in Supplementary information.

\section{RESULTS}

\subsection{XRD analysis}

The experimental results from our previous studies confirms that the PZS system contains $t-\mathrm{ZrO}_{2}$ as a unique component at $1100{ }^{\circ} \mathrm{C}$ and this undergoes partial degradation to $m-\mathrm{ZrO}_{2}$ at $1200{ }^{\circ} \mathrm{C}$ (supplementary information Figure S1). The XRD patterns obtained from the GDZS samples recorded after heat treatment at $1200{ }^{\circ} \mathrm{C}$ are illustrated in Figure 1a. The compositions containing lower concentrations of $\mathrm{Gd}^{3+}$ and $\mathrm{Dy}^{3+}\left(\mathrm{GDZS}-5\right.$ and GDZS-10) show $t-\mathrm{ZrO}_{2}$ as a solitary crystalline phase. A partial phase transition with $t-\rightarrow c-\mathrm{ZrO}_{2}$ is apparent for GDZS-20 (Figure $1 a$ inset) and for all the compositions that contained higher $\mathrm{Gd}^{3+}$ and $\mathrm{Dy}^{3+}$ concentrations (GDZS30 and GDZS-50) only $c-\mathrm{ZrO}_{2}$ was present as a solitary phase. The phase behaviour at $1300{ }^{\circ} \mathrm{C}$ (Figure $1 \boldsymbol{b}$ ) is similar to that found at $1200{ }^{\circ} \mathrm{C}$ for all the GDZS compositions. Although, very small amounts of $m-\mathrm{ZrO}_{2}, c-\mathrm{SiO}_{2}$ and $\mathrm{ZrSiO}_{4}$ are seen for compositions with $\mathrm{Gd}^{3+}$ and $\mathrm{Dy}^{3+}$ 
additions in the range of 5 - 20 wt. \% (GDZS-5, GDZS-10 and GDZS-20). However, $c-\mathrm{ZrO}_{2}$ as a distinct phase is retained for GDZS compositions with high $\mathrm{Gd}^{3+}$ and $\mathrm{Dy}^{3+}$ content (GDZS-30 and GDZS-50) at $1300{ }^{\circ} \mathrm{C}$. The XRD patterns of the powders heat treated at $1400{ }^{\circ} \mathrm{C}$ (Figure 1c) indicate $\mathrm{ZrSiO}_{4}$ as a major component alongside minor amounts of $t-\mathrm{ZrO}_{2}$ and $c-\mathrm{SiO}_{2}$ for all the compositions barring GDZS-50 that still displayed solitary $c-\mathrm{ZrO}_{2}$.

\subsection{Raman spectra}

Figure 2 presents the Raman spectra for all the powders recorded after heat treatment at $1200{ }^{\circ} \mathrm{C}$ and the GDZS-50 at $1400{ }^{\circ} \mathrm{C}$. The $148,268,320,465,650 \mathrm{~cm}^{-1}$ bands pertaining to $t-\mathrm{ZrO}_{2}{ }^{28}$ are clearly observed for GDZS-5 and at a slightly reduced intensity for GDZS-10, however with GDZS-20 the bands are only slightly more intense than the background. The bands characteristic of $c-\mathrm{ZrO}_{2}$ are at 618,305 and $140 \mathrm{~cm}^{-1} \cdot{ }^{13,29}$ For GDZS-30 only the band at $618 \mathrm{~cm}^{-1}$ is evident and shifted towards a lower wave number. This shift, although less marked is also seen with GDZS50 with the 618 and $305 \mathrm{~cm}^{-1}$ bands. GDZS-50 displayed enhancement in the intensity of the bands that correspond to $c-\mathrm{ZrO}_{2}$ at $1400{ }^{\circ} \mathrm{C}$ with a reduced shift and this infers the formation of highly crystalline $c-\mathrm{ZrO}_{2}$. Thus the observations from Raman spectra are consistent with the XRD results.

\subsection{Transmission electron microscopy}

TEM micrographs for GDZS-50 at $1400{ }^{\circ} \mathrm{C}$ are displayed in Figure 3. A clustered dispersion of larger sized $\mathrm{ZrO}_{2}$ grains in the glassy $\mathrm{SiO}_{2}$ matrix is evident in Figure $\mathbf{3 a}$. Figures $\mathbf{3} \boldsymbol{b}$ and $\mathbf{3} \boldsymbol{c}$ display a homogeneous distribution of multi-grain crystalline $\mathrm{ZrO}_{2}$ clusters embedded in the $\mathrm{SiO}_{2}$ matrix. The electron diffraction patterns (Figure 3d) affirmed the existence of diffraction planes that can be indexed to $c-\mathrm{ZrO}_{2}$. The glassy nature of the $\mathrm{SiO}_{2}$ is revealed through Figure $3 \boldsymbol{e}$ in which diffraction spots were negligible. Elemental mapping obtained via EDX microanalysis for the GDZS-50 sample is displayed in Figure 4. The elemental maps indicate the widespread 
distribution of $\mathrm{ZrO}_{2}$ grains throughout the $\mathrm{SiO}_{2}$ matrix. The correlation of $\mathrm{Gd}^{3+}, \mathrm{Dy}^{3+}$ and $\mathrm{Zr}^{4+}$ presence at the same positions affirms the $\mathrm{Gd}^{3+}$ and $\mathrm{Dy}^{3+}$ are accommodated on the lattice sites of $\mathrm{ZrO}_{2}$.

\subsection{Quantitative analysis}

The phase fractions and lattice parameters determined from Rietveld refinement are presented in Table 2. The refined diffraction pattern of GDZS-5 (Figure $5 \boldsymbol{a}$ ) at $1200{ }^{\circ} \mathrm{C}$ corresponds to the structure of $t-\mathrm{ZrO}_{2}$ with a tetragonal unit cell space group 137, P42/nmc. The pattern of GDZS50 (Figure $5 \boldsymbol{b}$ ) at $1400{ }^{\circ} \mathrm{C}$ shows the $c-\mathrm{ZrO}_{2}$ structure space group $225, \mathrm{Fm}-3 m(225)$. The refined data (Table 2) at $1200{ }^{\circ} \mathrm{C}$ confirms the formation of $t-\mathrm{ZrO}_{2}$ as a sole phase for GDZS-5 and GDZS-10, whereas its complete conversion to the $c-\mathrm{ZrO}_{2}$ phase is found for GDZS-20, GDZS-30 and GDZS-50. The refined lattice data for $t-\mathrm{ZrO}_{2}$ reveals steady increase in the $a=b$-axis values and a simultaneous reduction in the $c$-axis with increasing $\mathrm{Gd}^{3+}$ and $\mathrm{Dy}^{3+}$ additions. A similar trend of steady increment in lattice parameters with increasing $\mathrm{Gd}^{3+}$ and $\mathrm{Dy}^{3+}$ additions is witnessed for $c-\mathrm{ZrO}_{2}$ stabilized systems. This is a reasonable observation, which is justified by comparing the lattice parameters of standard $t-\mathrm{ZrO}_{2}(a=b=3.5957 \AA$ and $c=5.1844 \AA$ for ICDD card No. 01-079-1765) and standard $c-\mathrm{ZrO}_{2}(a=b=c=5.100 \AA$ for ICDD card No. 01-0714810). The $a=b$-axis value of standard $t-\mathrm{ZrO}_{2}\left\langle c-\mathrm{ZrO}_{2}\right.$, while $c$-axis value of standard $\left.t-\mathrm{ZrO}_{2}\right\rangle$ $c-\mathrm{ZrO}_{2}$. Therefore, the results that highlights the corresponding enhancement and reduction of $a$ $=b$-axis and $c$-axis of $t-\mathrm{ZrO}_{2}$ infers the critical role of $\mathrm{Gd}^{3+}$ and $\mathrm{Dy}^{3+}$ combination to impart $t-\rightarrow$ $c-\mathrm{ZrO}_{2}$ transition through their occupancy at the $\mathrm{Zr}^{4+}$ lattice sites. This mechanism is supported by the combined accommodation of $\mathrm{Gd}^{3+}$ and $\mathrm{Dy}^{3+}$ along the $a=b$-axis of $t-\mathrm{ZrO}_{2}$ resulting in its lattice expansion and simultaneous reduction along the $c$-axis that led to the $t-\rightarrow c-\mathrm{ZrO}_{2}$ transition. It is also apparent that a critical amount of $20 \mathrm{wt} . \% \mathrm{Gd}^{3+}$ and $\mathrm{Dy}^{3+}$ combination is sufficient to ensure $a=b$-axis expansion to accomplish the $t-\rightarrow c-\mathrm{ZrO}_{2}$ transition 
The presence of $c-\mathrm{SiO}_{2}$ and $m-\mathrm{ZrO}_{2}$ alongside dominant $t-\mathrm{ZrO}_{2}$ was determined from the refined data at $1300{ }^{\circ} \mathrm{C}$ for GDZS-5, GDZS-10 and GDZS 20. This indicates that heat treatment is an important factor for the crystallization of $c-\mathrm{SiO}_{2}$ and the $t-\mathrm{ZrO}_{2} \rightarrow m-\mathrm{ZrO}_{2}$ transition, which may be associated with the lattice expansion of $t-\mathrm{ZrO}_{2}$ and transformation on cooling.

However, the absence of $m-\mathrm{ZrO}_{2}$ in GDZS-30 and GDZS-50 at $1300{ }^{\circ} \mathrm{C}$ confirms that the crystallization of $c-\mathrm{ZrO}_{2}$ in a $\mathrm{ZrO}_{2}-\mathrm{SiO}_{2}$ system is highly stable and does not undergo transformation to $t-\mathrm{ZrO}_{2}$ or $m-\mathrm{ZrO}_{2}$ on cooling. Further thermal treatment to higher temperatures triggers the reaction amongst $\mathrm{ZrO}_{2}$ and amorphous $\mathrm{SiO}_{2}$ to yield $\mathrm{ZrSiO}_{4}$ and this is confirmed from the refined data at $1400{ }^{\circ} \mathrm{C}$. The enhanced $\mathrm{ZrSiO}_{4}$ crystallization is found in $t-\mathrm{ZrO}_{2}$ stabilized GDZS systems whereas the delayed $\mathrm{ZrSiO}_{4}$ crystallization is detected in $c-\mathrm{ZrO}_{2}$ stabilized GDZS systems. Moreover, there is a decline in $\mathrm{ZrSiO}_{4}$ formation with increasing $\mathrm{Gd}^{3+}$ and $\mathrm{Dy}^{3+}$ additions and there is a complete absence of $\mathrm{ZrSiO}_{4}$ in GDZS-50. However, the absence of any significant trend for the phase content of $c-\mathrm{SiO}_{2}$ in the GDZS systems suggests that $c-\mathrm{SiO}_{2}$ crystallization is an independent phenomenon that is not influenced by the formation of $\mathrm{ZrO}_{2}$ polymorphs present in the $\mathrm{ZrO}_{2}-\mathrm{SiO}_{2}$ system.

\subsection{Morphological analysis}

Secondary electron (SE) micrographs (Figures $\mathbf{6} \boldsymbol{a}, \mathbf{6} \boldsymbol{b}$ and $\mathbf{6} \boldsymbol{c}$ ) indicate the widespread distribution of crystalline $\mathrm{ZrO}_{2}$ particles throughout the intermittently aligned non-crystalline phase and these particles are found vary in size and shape. However, close observation shows that the particles are embedded in a matrix like structure. The EDX spectrum obtained from spot analysis for the grain indicated by a cross in Figure $\boldsymbol{6} \boldsymbol{c}$ shows the presence of Gd, Dy, $\mathrm{Zr}$ and $\mathrm{O}$ elements in significant quantity, which confirms that the embedded grains are $\mathrm{ZrO}_{2}$ and the matrix is amorphous $\mathrm{SiO}_{2}$. Moreover, the presence of $\mathrm{Gd}$ and Dy elements in equal proportion affirms their respective 
addition as precursors during the synthesis. These observations exhibit good corroboration with the elemental analysis determined from TEM.

\subsection{Mechanical behaviour}

Table 3 illustrates the density and mechanical data of PZS system at $1100{ }^{\circ} \mathrm{C}$ and GDZS-50 at $1400{ }^{\circ} \mathrm{C}$. Five different measurements were performed to obtain the mean value and standard deviation of density and fracture toughness. The elastic modulus and hardness data were derived from ten different indents at random locations. The load vs. depth nanoindentation profiles of GDZS-50 (Figure 7) were found to be highly uniform and consistent. The mechanical data recorded for the PZS is found lower than the reported values available in the literature $\mathrm{e}^{30,31}$ and this is believed to be a consequence of the high $\mathrm{SiO}_{2}$ content, inadequate densification due to the low temperature sintering $\left(1100{ }^{\circ} \mathrm{C}\right)$ and the employed synthetic conditions. The presence of radial cracks (indicated by the arrow marks) due to indentation on the polished surface of GDZS50 are shown in Figure 8, fracture toughness was calculated from the length of the se cracks (equation 1). The enhanced thermal stability of GDZS-50 is demonstrated by its highly dense nature. The density and mechanical data of GDZS-50 are superior to the measured values of PZS. This suggests that $\mathrm{Gd}^{3+}$ and $\mathrm{Dy}^{3+}$ additions induce improved phase stability of GDZS-50 at elevated heat treatment that results in better densification and superior mechanical properties.

\subsection{MRI and CT imaging characteristics}

The room temperature magnetization curves of the GDZS system are shown in Figure 9 and Table 4 presents the calculated magnetic parameters obtained from the plotted curves. The results indicate the enhanced saturation magnetization (Ms) with simultaneous increase in $\mathrm{Gd}^{3+}$ and $\mathrm{Dy}^{3+}$ additions. The presence of poor hysteresis loops confirms the paramagnetic behaviour of $\mathrm{Gd}^{3+}$ and $\mathrm{Dy}^{3+}$ in $\mathrm{ZrO}_{2}-\mathrm{SiO}_{2}$ systems. Nonetheless, the in-vitro MRI and $\mathrm{CT}$ data displays positive contrast behaviour for the GDZS-50 sample that are presented in Figure 10, 11 and 12. $\mathrm{T}_{1}$ 
weighted MR images (Figure 10) show enhanced brightness for the increasing GDZS-50 concentrations and an ascending trend is observed for the relaxivity values. The continuous rise in $1 / T_{2}$ values and diminution in brightness of $T_{2}$ weighted MR images with respect to the increasing GDZS-50 concentrations are evident from Figure 11. Also, CT phantom images (Figure 12) display the enhanced brightness for the increasing GDZS-50 concentration and the same trend is reflected for the recorded Hounsfield unit values.

\subsection{Cytotoxicity Tests}

The results from the cytotoxicity tests (Figure 13) revealed the absence of significant toxicity upon the treatment of PZS and GDZS-5 samples up to $200 \mu \mathrm{g} / \mathrm{ml}$ of concentration. We observed a marginal reduction in the cell viability upon the treatment of GDZS-10 and GDZS-20 samples. In case of higher $\mathrm{Gd}^{3+}$ and $\mathrm{Dy}^{3+}$ containing samples (GDZS-30 and GDZS-50), a significant reduction in the cell viability is observed with higher concentrations. The MG-63 cells incubated with maximal concentrations $(200 \mu \mathrm{g} / \mathrm{ml})$ of PZS or GDZS-10 or GDZS-30 or GDZS-50 compositions were subjected to morphological analysis using optical microscope. No significant morphological changes are observed in the MG-63 cells upon treatment with the PZS and GDZS samples (Figure 14).

On further investigation of biocompatibility of the investigated materials, a live/dead staining assay was used with the MG-63 cells after incubating with PZS and GDZS samples. The fluorescence micrographs of MG-63 cells (Figure 15) depict live cells stained as green while the dead cells stained as red. These fluorescence micrographs demonstrate the presence of live cells in green colour with devoid of dead cells in PZS and GDZS-10 whereas the presence of dead cells (exemplary cells are indicated by arrow marks) coloured in red are obvious for GDZS-30 and GDZS-50. 


\subsection{ALP (Alkaline phosphatase) gene expression analysis}

During the differentiation of osteoblast cells, ALP is expressed as a key enzyme and it is also considered as a marker enzyme for osteoblast proliferation. The ALP gene expression in MG-63 cell line were determined using qRT-PCR upon the treatment of PZS, GDZS-10, GDZS-30 and GDZS-50 samples. The ALP expression was not altered in the cells which were treated with PZS and GDZS-10 samples indicating the unperturbed proliferation capacity of the MG-63 cells. However, the ALP expression is reduced by $10 \%$ and $24 \%$ in the cells which were treated with GDZS-30 and GDZS-50 samples respectively (Figure 16).

\section{DISCUSSION}

The results from XRD and Raman data establish the combined influence of $\mathrm{Gd}^{3+}$ and $\mathrm{Dy}^{3+}$ to induce $t-\rightarrow c-\mathrm{ZrO}_{2}$ transition. The compositions $>10 \mathrm{wt} \% \mathrm{Gd}^{3+}$ and $\mathrm{Dy}^{3+}$ result in a comprehensive transformation to $c-\mathrm{ZrO}_{2}$ at $1200{ }^{\circ} \mathrm{C}$. Further heat treatment activated the simultaneous occurrence of $c-\mathrm{SiO}_{2}$ crystallization and $t-\rightarrow m-\mathrm{ZrO}_{2}$ transition in a minor level for $t-\mathrm{ZrO}_{2}$ stabilized systems. Moreover, heat treatment beyond $1300{ }^{\circ} \mathrm{C}$ resulrs un the formation of $\mathrm{ZrSiO}_{4}$ for all compositions, with the exception of GDZS-50 that preserve $c-\mathrm{ZrO}_{2}$ in amorphous $\mathrm{SiO}_{2}$ matrix till $1400{ }^{\circ} \mathrm{C}$. The distribution of crystalline $c-\mathrm{ZrO}_{2}$ grain clusters throughout the $\mathrm{SiO}_{2}$ matrix is observed from TEM studies. The $\mathrm{Gd}^{3+}$ and $\mathrm{Dy}^{3+}$ accommodation in the $\mathrm{ZrO}_{2}$ lattice is confirmed from the EDX spectra and elemental mapping.

The Rietveld refinement results revealed a $t-\rightarrow c-\mathrm{ZrO}_{2}$ transition due to the accommodation of $\mathrm{Gd}^{3+}$ and $\mathrm{Dy}^{3+}$ along the $a=b$-axis lattice sites of $\mathrm{ZrO}_{2}$ and this is established from the obvious enhancement in $a=b$-axis values and decline in $c$-axis values of $t-\mathrm{ZrO}_{2}$. The observation of enhanced $\mathrm{ZrSiO}_{4}$ crystallization in $t-\mathrm{ZrO}_{2}$ stabilized systems and its formation in minor level in case of $c-\mathrm{ZrO}_{2}$ stabilized GDZS systems infers that $t-\mathrm{ZrO}_{2}$ is more susceptible to react with glassy $\mathrm{SiO}_{2}$ in comparison with $c-\mathrm{ZrO}_{2}$. This inference corroborates with the report of $\mathrm{Itoh}^{28}$ that reported 
enhanced kinetics between $t-\mathrm{ZrO}_{2}$ and amorphous $\mathrm{SiO}_{2}$ rather than the slow kinetics that occurs between amorphous $\mathrm{ZrO}_{2}$ and amorphous $\mathrm{SiO}_{2}$ in the $\mathrm{ZrO}_{2}-\mathrm{SiO}_{2}$ system.

The observation of minor $\mathrm{ZrSiO}_{4}$ formation even with $c-\mathrm{ZrO}_{2}$ stabilized compositions and its absence for the maximum $\mathrm{Gd}^{3+}$ and $\mathrm{Dy}^{3+}$ doped composition (GDZS-50) is explained by the observations based on our previous investigations reported on $\mathrm{La}^{3+}(\mathrm{LZS}), \mathrm{Gd}^{3+}(\mathrm{GZS}), \mathrm{Ce}^{4+}$ $(\mathrm{CZS})$ and $\mathrm{Dy}^{3+}(\mathrm{DZS})$ additions in $\mathrm{ZrO}_{2}-\mathrm{SiO}_{2}$ binary systems. ${ }^{10-13}$ The considerable size difference between $\mathrm{La}^{3+}(1.06 \AA)$ and $\mathrm{Zr}^{4+}(0.79 \AA)$ restricts the entry of $\mathrm{La}^{3+}$ into the $\mathrm{ZrO}_{2}$ lattice and as a consequence the quantitative analysis implies negligible changes in the lattice data of $t$ $\mathrm{ZrO}_{2}$ in LZS systems. The smaller ionic size of $\mathrm{Ce}^{4+}(0.97 \AA)$ than $\mathrm{La}^{3+}$ permits the entry of $\mathrm{Ce}^{4+}$ at the $t-\mathrm{ZrO}_{2}$ lattice until $20 \mathrm{wt} . \%$ additions in CZS system. Beyond this limit, the excess $\mathrm{Ce}^{4+}$ is rejected from the $\mathrm{ZrO}_{2}$ lattice and individually precipitates as $c-\mathrm{CeO}_{2}$ at ambient conditions. $\mathrm{Gd}^{3+}$ $(0.94 \AA)$ has a smaller ionic size than $\mathrm{Ce}^{4+}$ and this favours the additional accommodation at the $\mathrm{ZrO}_{2}$ lattice till 25 wt. \%. Due to the accommodation of excess $\mathrm{Gd}^{3+}$, a gradual increase in the lattice parameter of $t-\mathrm{ZrO}_{2}$ and subsequent $t-\rightarrow c-\mathrm{ZrO}_{2}$ transition occurs in GZS system. Nonetheless, the predominant presence of $\mathrm{ZrSiO}_{4}$ at $1200{ }^{\circ} \mathrm{C}$ for low $\mathrm{Gd}^{3+}$ additions and its reduced existence for higher $\mathrm{Gd}^{3+}$ additions infers that $c-\mathrm{ZrO}_{2}$ is less reactive with $\mathrm{SiO}_{2}$ in comparison with $t-\mathrm{ZrO}_{2}$. In the case of the DZS system, the $\mathrm{ZrO}_{2}$ lattice prefers to host a maximum of 50 wt. $\% \mathrm{Dy}^{3+}$ ions, which is mainly due to the lower ionic radius of $\mathrm{Dy}^{3+}(0.91 \AA)$ compared with other investigated rare earth elements. This hypothesis is confirmed from the quantitative analysis results in which a continuous expansion of the $t-\mathrm{ZrO}_{2}$ lattice and its associated $t-\rightarrow c$ $\mathrm{ZrO}_{2}$ transition is witnessed in DZS systems. It is worth noting that $c-\mathrm{ZrO}_{2}$ experiences higher lattice expansion in GZS system rather than DZS systems.

In the present GDZS system, the combined size effect of $\mathrm{Gd}^{3+}$ and $\mathrm{Dy}^{3+}[(0.94+0.91) / 2=0.925$ $\AA$ ] is less than $\mathrm{Gd}^{3+}$ and this facilitates their excess accommodation in the $\mathrm{ZrO}_{2}$ lattice and as a 
consequence the maximum lattice expansion of $c-\mathrm{ZrO}_{2}$ is determined for GDZS-50, which remains stable until $1400{ }^{\circ} \mathrm{C}$ devoid of $\mathrm{ZrSiO}_{4}$ formation that was encountered previously in the GZS system. Therefore, the ionic radii of dopants, quantity of the dopant concentration and associated lattice expansion are all factors that determine the $t-\rightarrow c-\mathrm{ZrO}_{2}$ transition and the resultant structural stability of $c-\mathrm{ZrO}_{2}$. Consequently, the enhanced reaction kinetics with respect to temperature created by the $\mathrm{Gd}^{3+}$ and $\mathrm{Dy}^{3+}$ combinations that induce $t-\rightarrow c-\mathrm{ZrO}_{2}$ transitions in GDZS system suppresses the crystallization of amorphous $\mathrm{SiO}_{2}$ even at $1400{ }^{\circ} \mathrm{C}$. Moreover, the preservation of $\mathrm{SiO}_{2}$ in amorphous state is highly beneficial for bone implant applications. ${ }^{29}$

The SEM studies also reveal the embeddingt of crystalline $\mathrm{ZrO}_{2}$ grains throughout the glassy $\mathrm{SiO}_{2}$ matrix that yields enhanced mechanical properties. The mechanical features of GDZS-50 are thus superior to the DZS and CZS systems. Also, the elastic modulus of GDZS-50 is $23 \%$ higher than Y-TZP and exhibit good matches with the zirconia toughened alumina (ZTA) system whose elastic modulus is reported in the range of $280-300 \mathrm{GPa} \cdot{ }^{32-34}$ The fracture toughness of GDZS-50 is higher than alumina ceramics and marginally lower than Y-TZP. ${ }^{3}$ It is worth noting that GDZS50 yields superior mechanical properties even in the presence of amorphous $\mathrm{SiO}_{2}$ whose concentration is equivalent to the molecular ratio of $\mathrm{ZrO}_{2}$. The mechanism behind the enhancement in density and mechanical data is attributed to the improved densification of amorphous $\mathrm{SiO}_{2}$ matrix and its reinforcement by the highly crystalline $\mathrm{ZrO}_{2}$ grains.

The presence of $\mathrm{Gd}^{3+}$ in GDZS-50 enhances the $\mathrm{T}_{1}$ weighted MRI contrast ability and in addition the presence of $\mathrm{Dy}^{3+}$ in GDZS-50 yields both significant $\mathrm{T}_{2} \mathrm{MRI}$ and CT contrast ability that is confirmed by in-vitro imaging studies. Maximal $\mathrm{Gd}^{3+}$ and $\mathrm{Dy}^{3+}$ containing samples (GDZS-50) are toxic to the MG-63 cells. The level of toxicity was higher when the cells are treated with higher concentration $(200 \mu \mathrm{g} / \mathrm{ml})$ of GDZS-50 samples. However, the level of cytotoxicity is less than $20 \%$ when the cells are treated with the lower concentration of GDZS-50 samples. Overall studies 
enlighten the superior mechanical features of GDZS-50 allied with multi-modal imaging contrast features and biocompatibility.

\section{CONCLUSIONS}

The $t-\rightarrow c-\mathrm{ZrO}_{2}$ transition in $\mathrm{ZrO}_{2}-\mathrm{SiO}_{2}$ system with respect to increased $\mathrm{Gd}^{3+}$ and $\mathrm{Dy}^{3+}$ additions is accompanied by their incorporation at the $\mathrm{ZrO}_{2}$ lattice sites. The phase stability of $c-\mathrm{ZrO}_{2}$ is retained till $1400{ }^{\circ} \mathrm{C}$ for the maximum $\mathrm{Gd}^{3+}$ and $\mathrm{Dy}^{3+}$ co-substitutions in $\mathrm{ZrO}_{2}-\mathrm{SiO}_{2}$ systems and this effect is reflected in the resulting highly crystalline and dense material. The $\mathrm{Gd}^{3+}$ and $\mathrm{Dy}^{3+}$ content and its concomitant positive effects in lattice volume of $c-\mathrm{ZrO}_{2}$ plays a critical role in delaying $\mathrm{ZrSiO}_{4}$ crystallization at higher temperatures. The mechanical strength of GDZS-50 is determined to be superior to the commercially available synthetic bone implants. Multi-modal imaging contrast features of GDZS-50 are documented. In vitro analysis suggests the low cell toxicity and confirms the biocompatibility of the materials.

\section{Supporting Information}

The following Supporting Information is available free of charge on the ACS Publications website at DOI https://pubs.acs.org/doi/suppl/10.1021/acs.inorgchem.8b00337

Cytotoxicity Tests, Live/Dead staining, Quantitative RT-PCR, Primers used in qRT-PCR and XRD patterns of pure $\mathrm{ZrO}_{2}-\mathrm{SiO}_{2}$ system at two different temperatures.

\section{ACKNOWLEDGEMENT}

The first author is thankful to the Commonwealth Scholarship Commission (CSC), UK for his split-site PhD scholarship. The financial assistance received from DST-SERB (Reference: EMR/2015/002200 dated 20.01.2016) India is acknowledged. The Instrumentation facility availed from the Central Instrumentation Facility (CIF) of Pondicherry University, India and School of Materials, University of Manchester, UK are greatly acknowledged. 


\section{List of Tables}

Table 1 Precursor concentrations used in the synthesis procedure

\begin{tabular}{|c|c|c|c|c|c|}
\hline \multirow{2}{*}{ Sample code } & \multicolumn{4}{|c|}{ Precursor concentrations (M) } & \multirow{2}{*}{$\begin{array}{l}\% \text { of } \mathrm{Gd}^{3+} \text { and } \mathrm{Dy}^{3+} \\
\text { with respect to } \mathrm{Zr}^{4+}\end{array}$} \\
\hline & $\mathrm{Dy}\left(\mathrm{NO}_{3}\right)_{3}$ & $\mathrm{Gd}\left(\mathrm{NO}_{3}\right)_{3}$ & $\mathrm{ZrOCl}_{2}$ & $\left(\mathrm{C}_{2} \mathrm{H}_{5} \mathrm{O}\right)_{4} \mathrm{Si}$ & \\
\hline $\mathbf{P Z S}$ & - & - & $0.5 \mathrm{M}$ & $0.5 \mathrm{M}$ & - \\
\hline GDZS-5 & $0.0125 \mathrm{M}$ & $0.0125 \mathrm{M}$ & $0.5 \mathrm{M}$ & $0.5 \mathrm{M}$ & 5 \\
\hline GDZS-10 & $0.0250 \mathrm{M}$ & $0.0250 \mathrm{M}$ & $0.5 \mathrm{M}$ & $0.5 \mathrm{M}$ & 10 \\
\hline GDZS-20 & $0.0500 \mathrm{M}$ & $0.0500 \mathrm{M}$ & $0.5 \mathrm{M}$ & $0.5 \mathrm{M}$ & 20 \\
\hline GDZS-30 & $0.0750 \mathrm{M}$ & $0.0750 \mathrm{M}$ & $0.5 \mathrm{M}$ & $0.5 \mathrm{M}$ & 30 \\
\hline GDZS-50 & $0.1250 \mathrm{M}$ & $0.1250 \mathrm{M}$ & $0.5 \mathrm{M}$ & $0.5 \mathrm{M}$ & 50 \\
\hline
\end{tabular}

Table 2 Refined structural parameters for the different GDZS compositions at specific temperatures

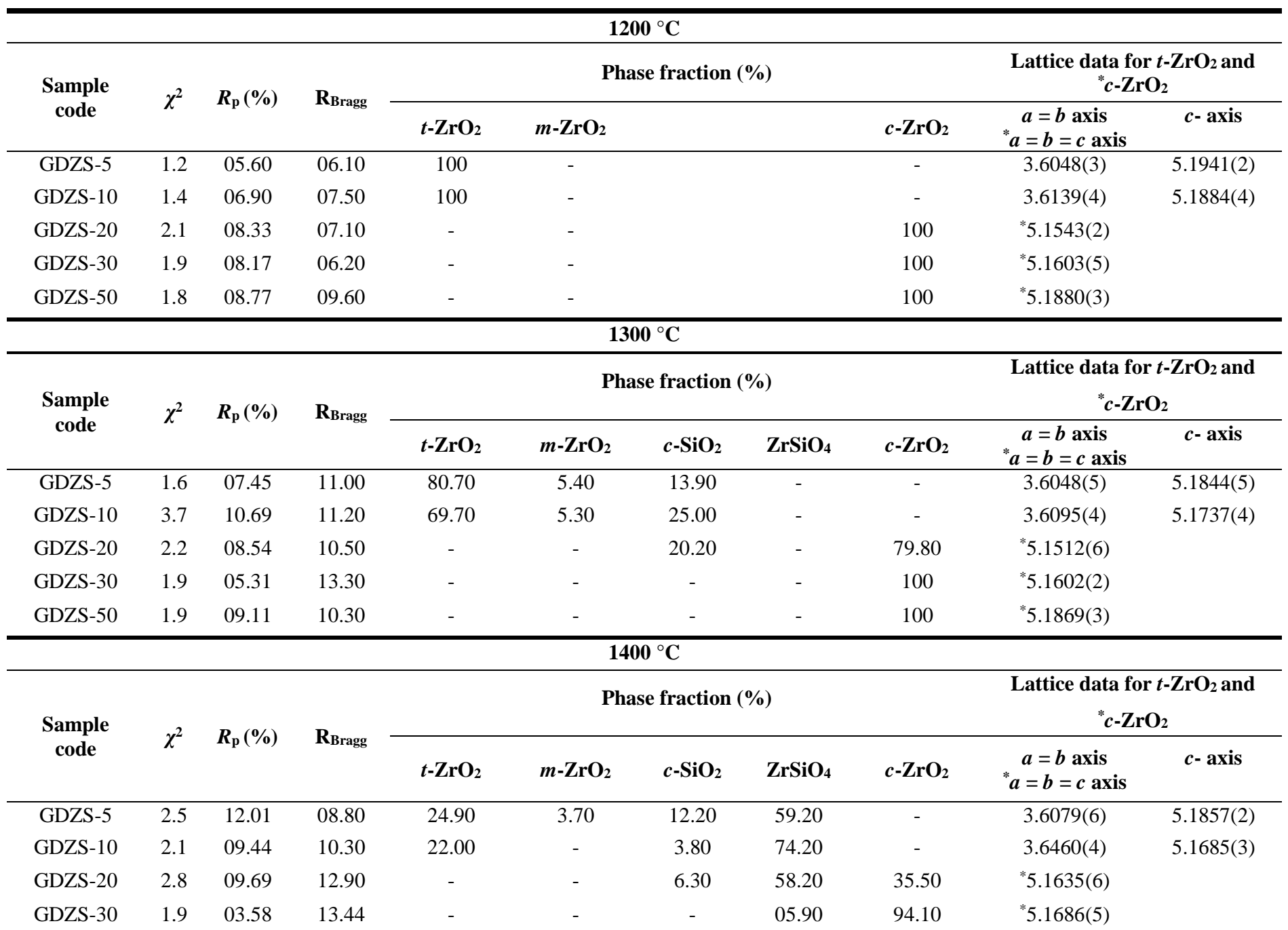


Table 3 Physical and mechanical properties of PZS and GDZS-50 compositions.

\begin{tabular}{ccccc}
\hline Sample & $\begin{array}{c}\text { Density } \\
\left(\mathbf{g m . c m}^{-3}\right)\end{array}$ & $\begin{array}{c}\text { Fracture Toughness } \\
\left(\mathbf{M P a}^{\mathbf{3}} \mathbf{m}^{\mathbf{2}}\right)\end{array}$ & $\begin{array}{c}\text { Hardness } \\
(\mathbf{G P a})\end{array}$ & $\begin{array}{c}\text { Elastic Modulus } \\
(\mathbf{G P a})\end{array}$ \\
\hline PZS & $3.79(0.03)$ & $1.31(0.58)$ & $0.45(0.50)$ & $6.81(1.00)$ \\
\hline GDZS-50 & $4.99(0.32)$ & $9.89(1.15)$ & $15.80(0.57)$ & $266.69(2.41)$ \\
\hline
\end{tabular}

Table 4 Magnetic properties of $\mathrm{Gd}^{3+}$ and $\mathrm{Dy}^{3+}$ doped $\mathrm{ZrO}_{2}-\mathrm{SiO}_{2}$ binary oxides.

\begin{tabular}{cccc}
\hline Sample code & Coercivity (G) & Magnetization (emu/g) & Retentivity (emu/g) \\
\hline GDZS-5 & 33.40 & $1.97 \times 10^{-3}$ & $10.90 \times 10^{-6}$ \\
\hline GDZS-10 & 20.93 & $3.09 \times 10^{-3}$ & $10.53 \times 10^{-6}$ \\
\hline GDZS-20 & 17.79 & $6.96 \times 10^{-3}$ & $13.97 \times 10^{-6}$ \\
\hline GDZS-30 & 13.53 & $12.34 \times 10^{-3}$ & $17.32 \times 10^{-6}$ \\
\hline GDZS-50 & 10.97 & $17.17 \times 10^{-3}$ & $22.27 \times 10^{-6}$ \\
\hline
\end{tabular}




\section{List of Figures}

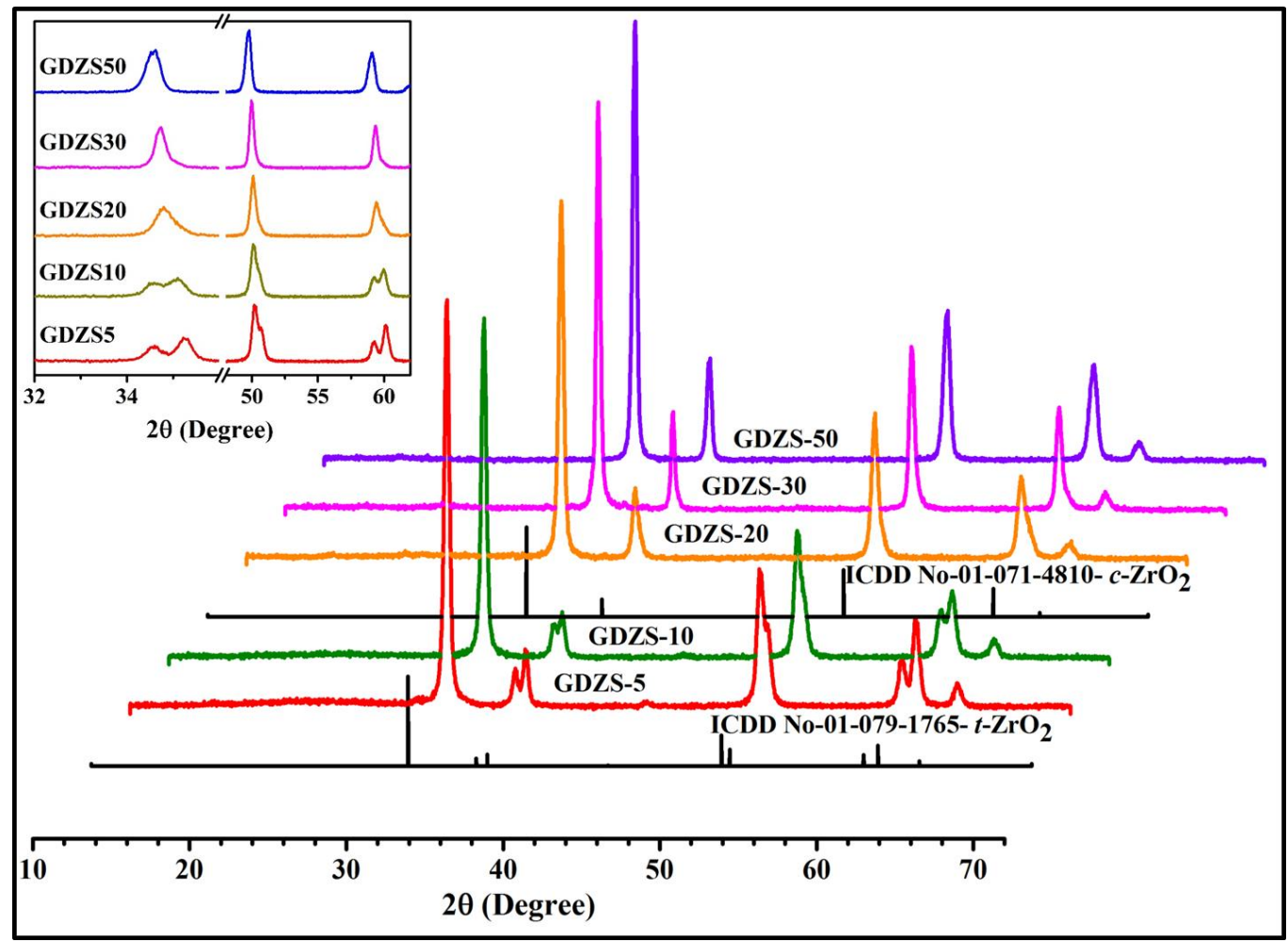

Figure 1a XRD patterns of $\mathrm{Gd}^{3+}$ and $\mathrm{Dy}^{3+}$ added $\mathrm{ZrO}_{2}-\mathrm{SiO}_{2}$ binary systems recorded after heat treatment at $1200{ }^{\circ} \mathrm{C}$

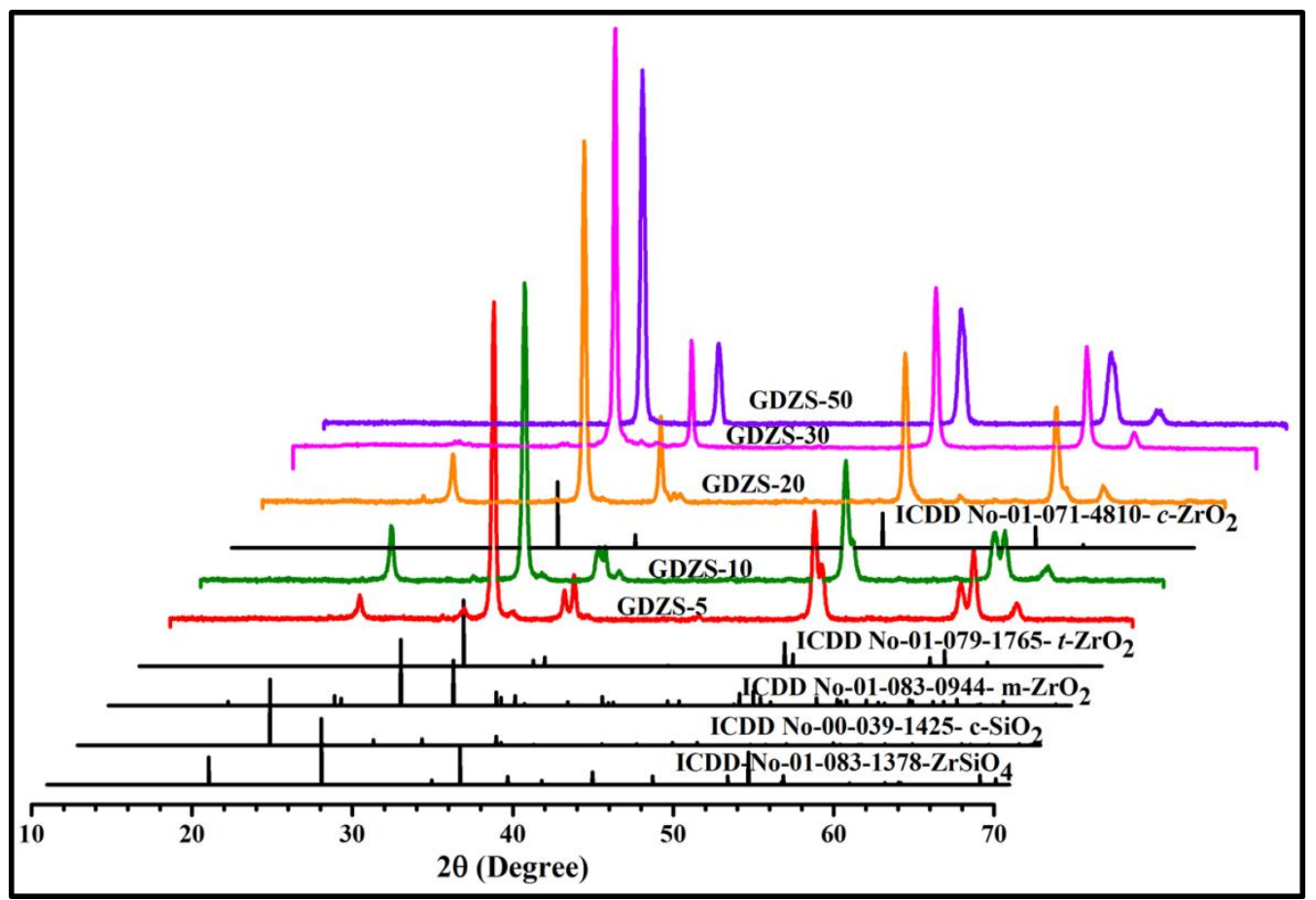

Figure 1b XRD patterns of $\mathrm{Gd}^{3+}$ and $\mathrm{Dy}^{3+}$ added $\mathrm{ZrO}_{2}-\mathrm{SiO}_{2}$ binary systems recorded after heat treatment at $1300{ }^{\circ} \mathrm{C}$ 


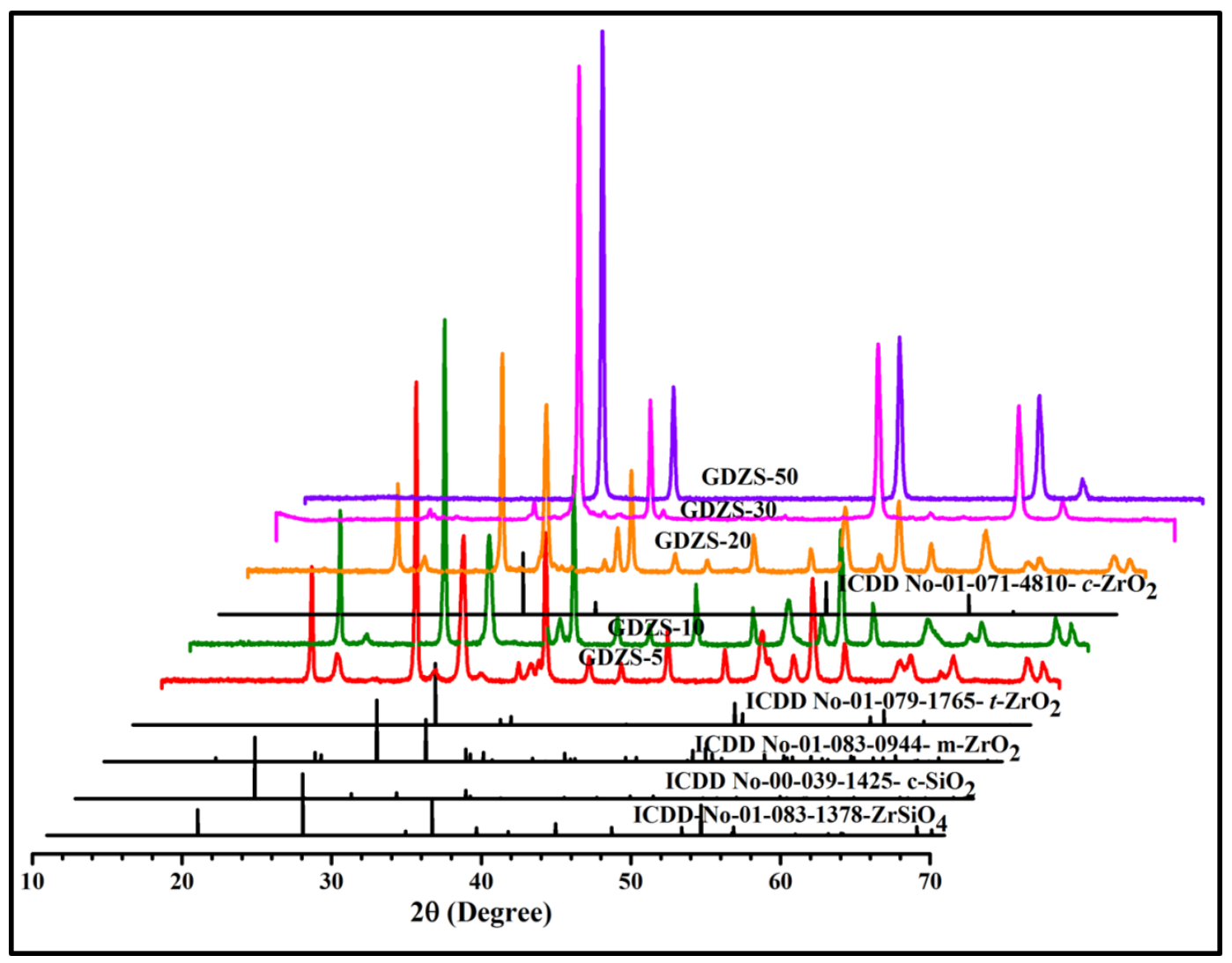

Figure 1c XRD patterns of $\mathrm{Gd}^{3+}$ and $\mathrm{Dy}^{3+}$ added $\mathrm{ZrO}_{2}-\mathrm{SiO}_{2}$ binary systems recorded after heat treatment at $1400{ }^{\circ} \mathrm{C}$

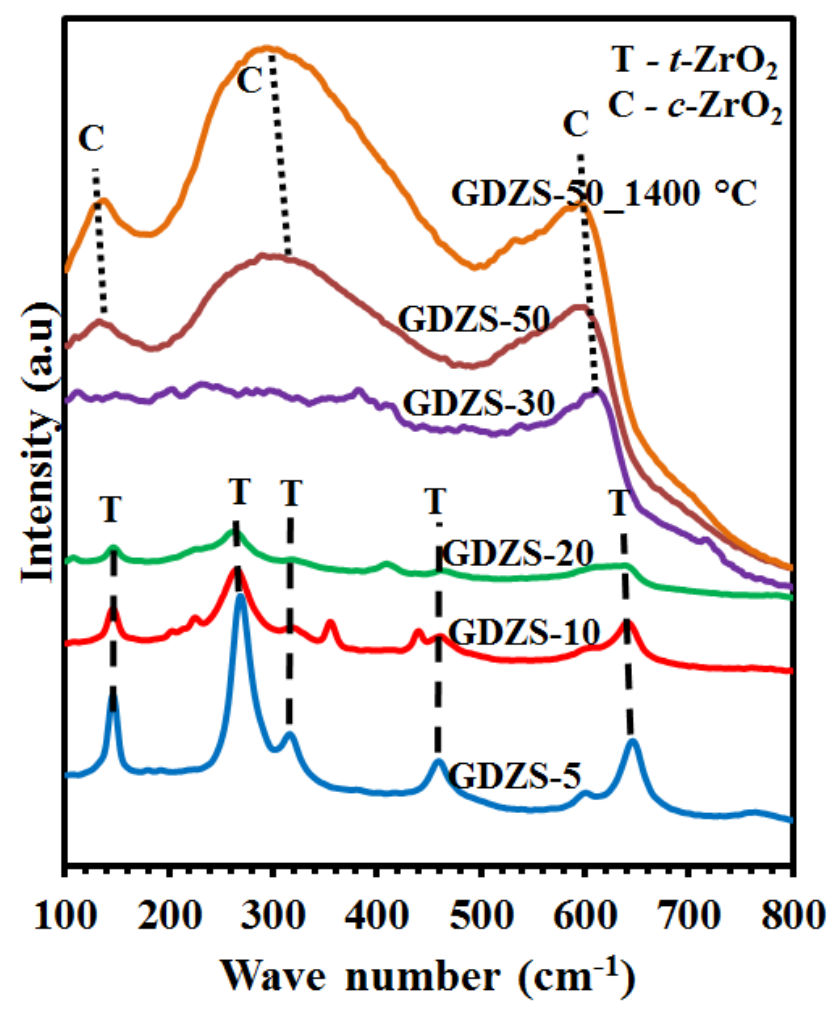

Figure 2 Raman spectra of GDZS samples recorded after heat treatment at $1200{ }^{\circ} \mathrm{C}$ and GDZS-50 at $1400{ }^{\circ} \mathrm{C}$. 

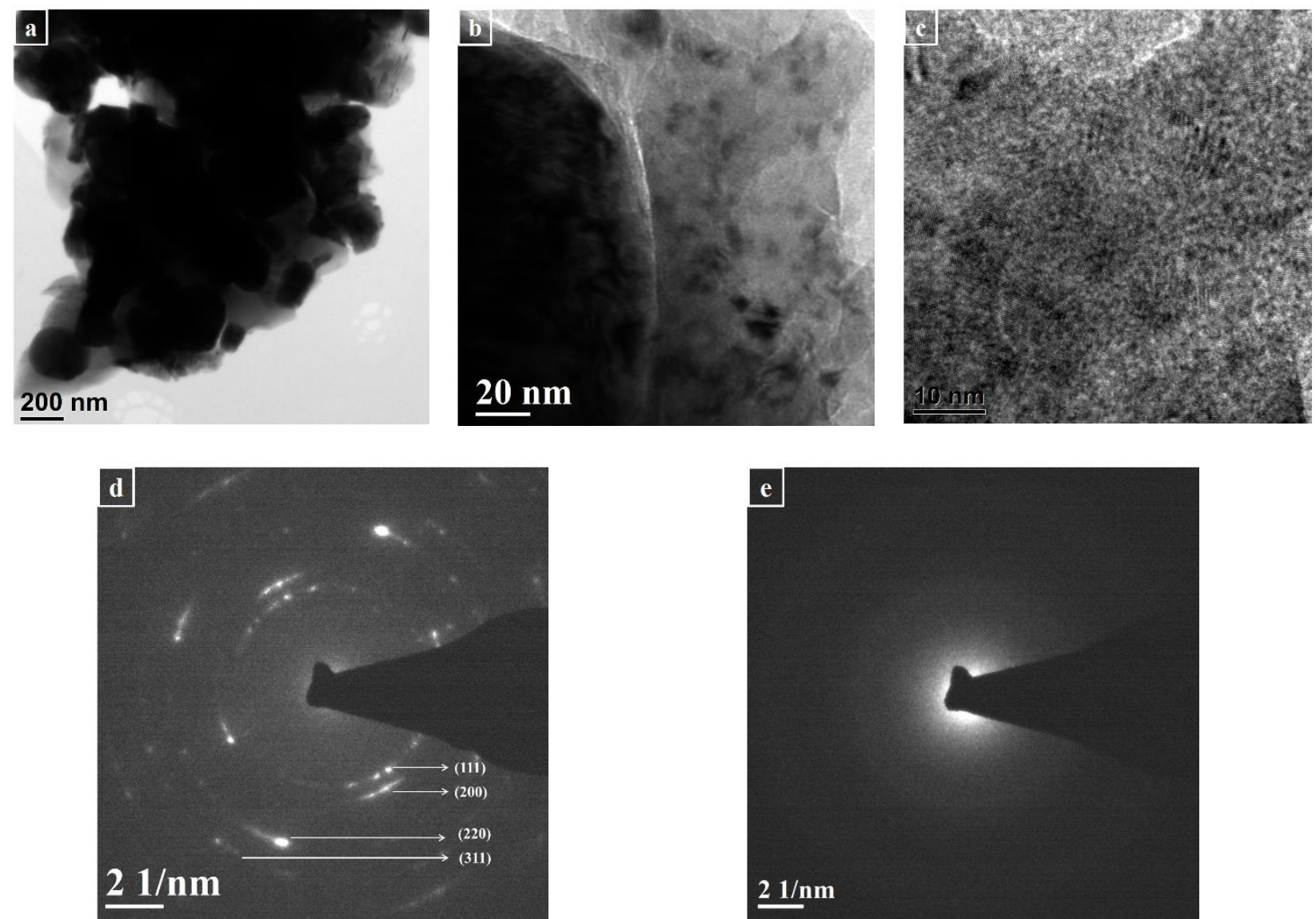

Figure 3 Transmission Electron micrographs (Figs. $3 a, 3 b$ and $3 c$ ) and SAED patterns (Figs. $3 d$ and $3 e$ ) of GDZS-50 at $1400{ }^{\circ} \mathrm{C}$. 


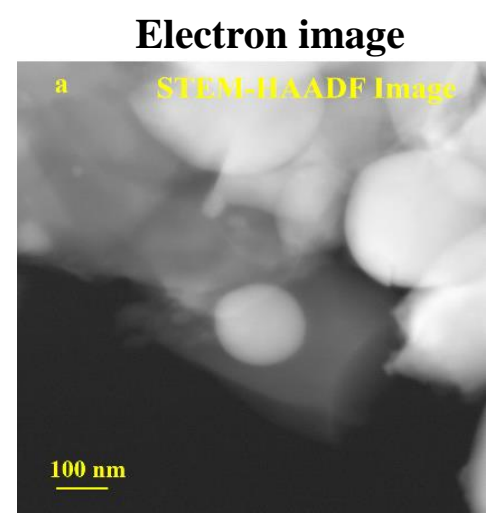

Zr K Series

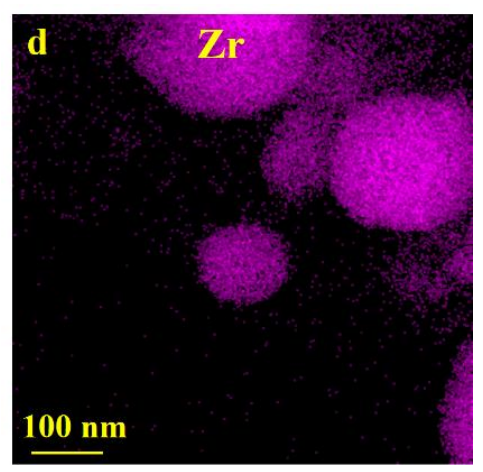

O K Series

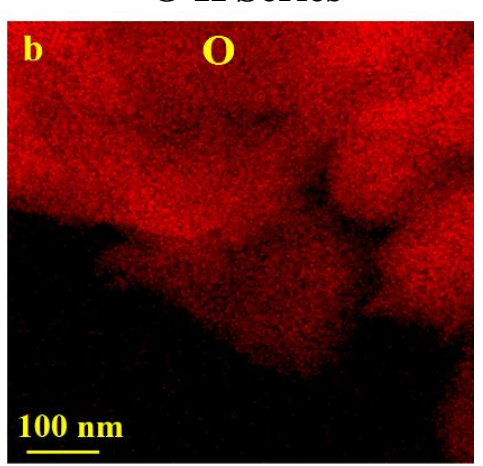

Gd K Series

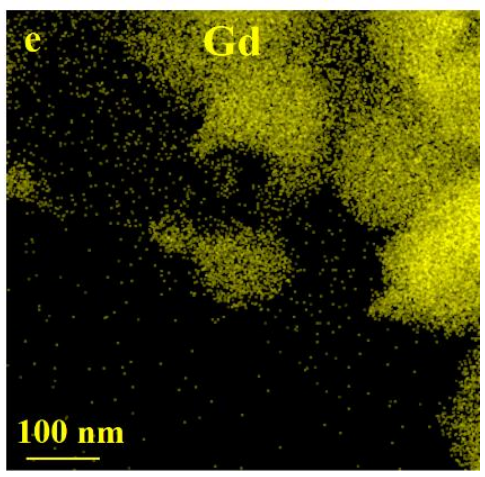

Si K Series

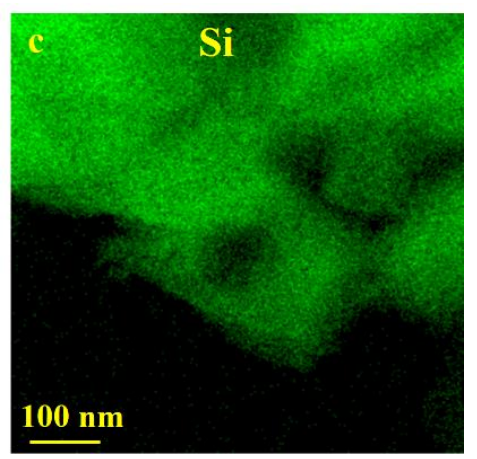

Dy K Series

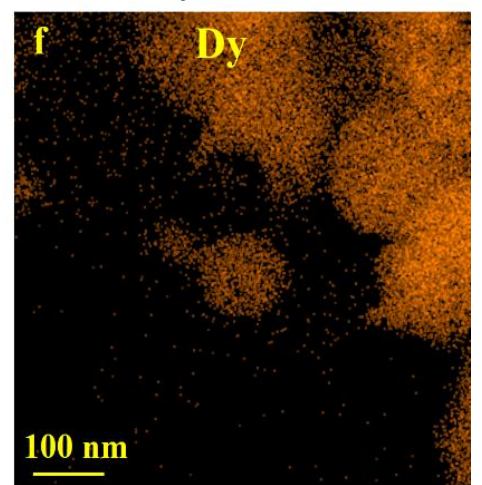

Figure 4 Elemental map of GDZS-50 at $1400{ }^{\circ} \mathrm{C}$ constructed from Scanning Transmission Electron Micrographs. 


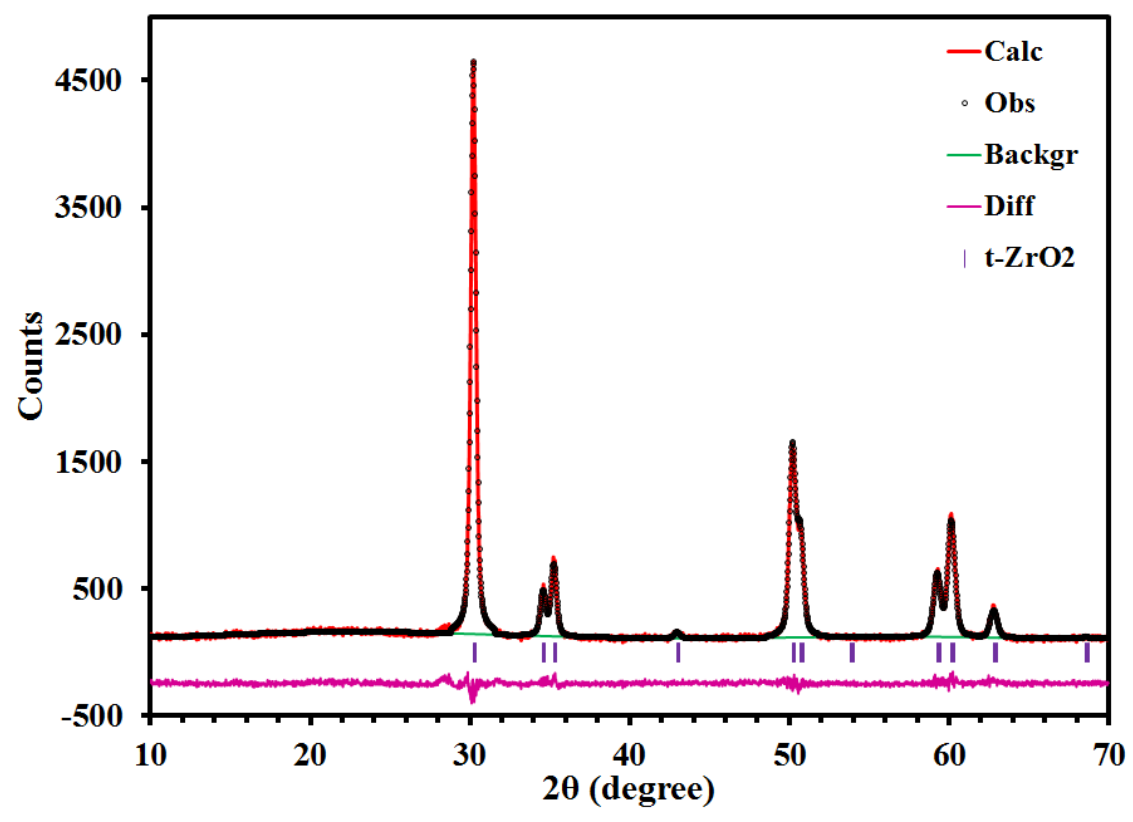

Figure $5 a \quad$ Refined powder diffraction patterns for GDZS-5 at $1200{ }^{\circ} \mathrm{C}$.

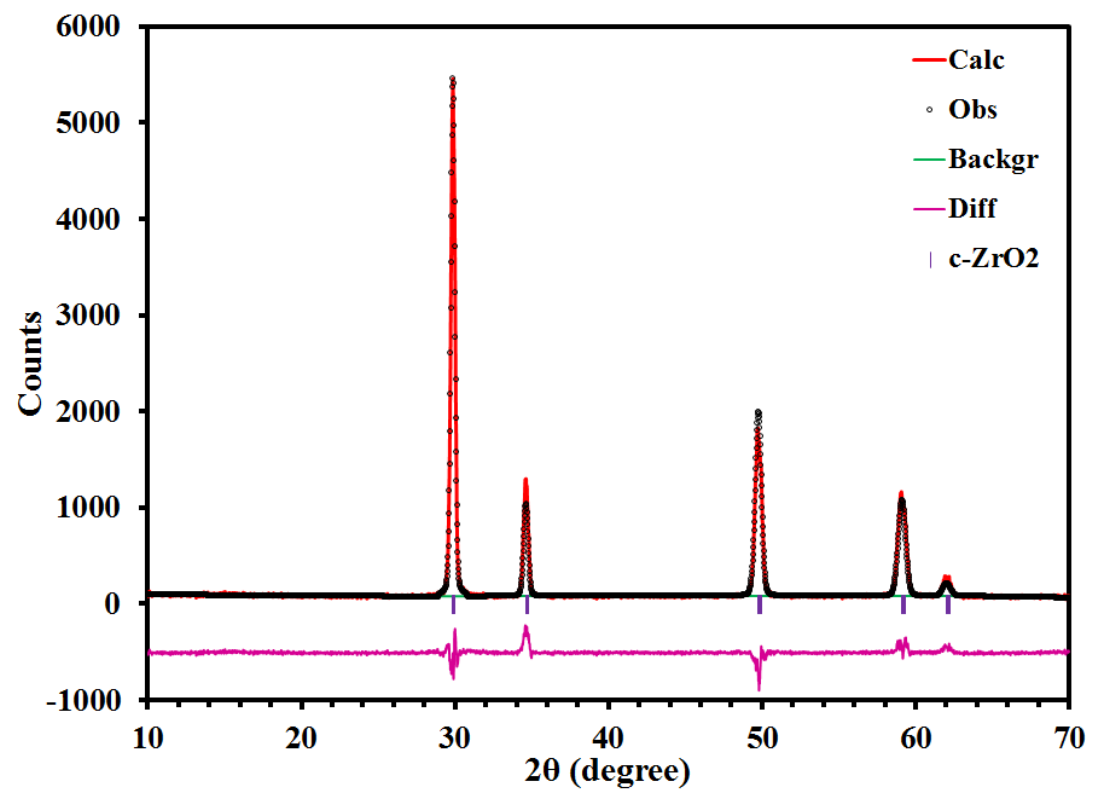

Figure $5 b$

Refined powder diffraction patterns for GDZS-50 at $1400{ }^{\circ} \mathrm{C}$. 

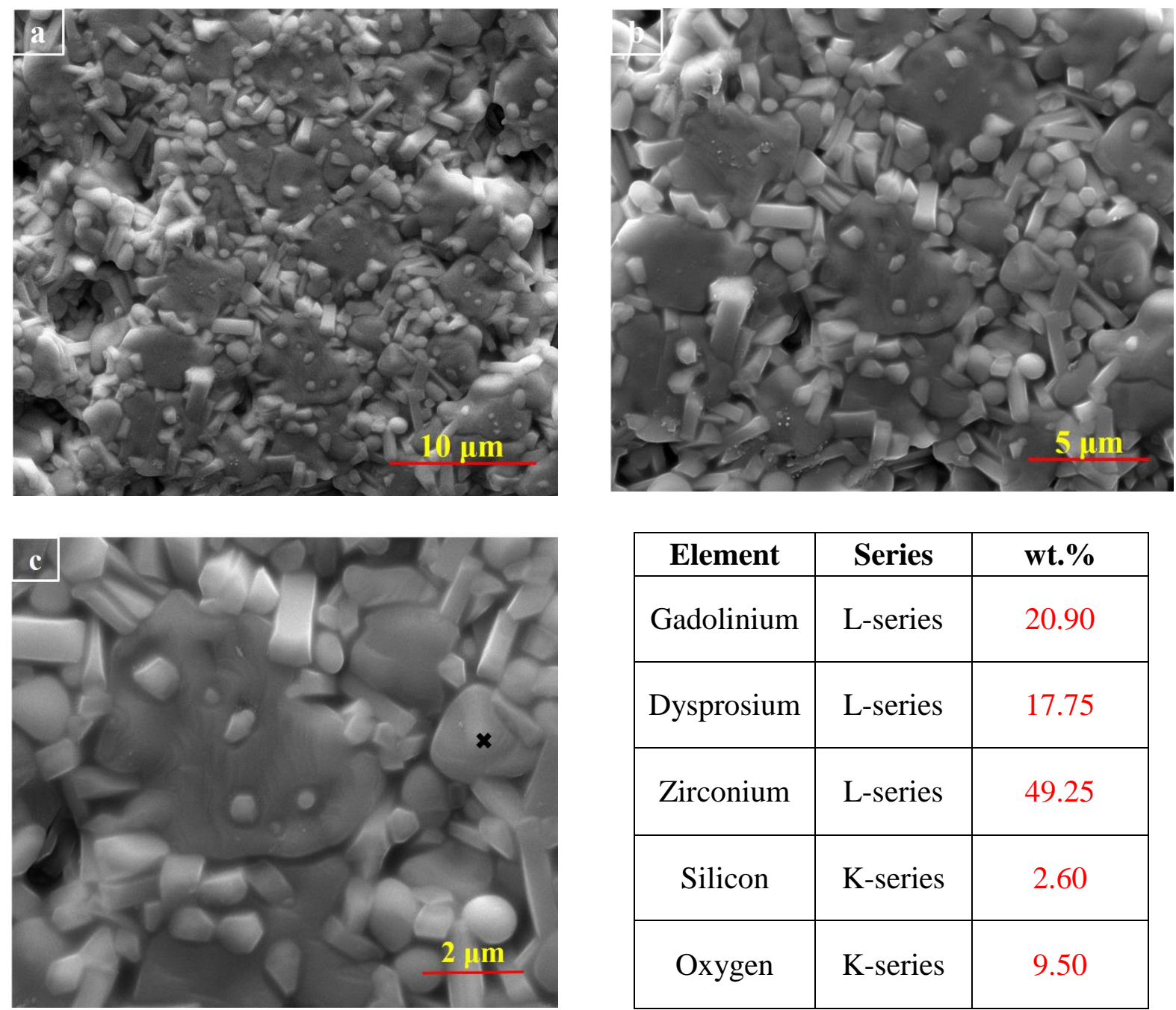

\begin{tabular}{|c|c|c|}
\hline Element & Series & wt.\% \\
\hline Gadolinium & L-series & 20.90 \\
\hline Dysprosium & L-series & 17.75 \\
\hline Zirconium & L-series & 49.25 \\
\hline Silicon & K-series & 2.60 \\
\hline Oxygen & K-series & 9.50 \\
\hline
\end{tabular}

Figure 6 Scanning electron micrographs of GDZS-50 sample heat treated at $1400{ }^{\circ} \mathrm{C}$ and EDX spectra recorded by spot analysis for the marked grain $(6 C)$.

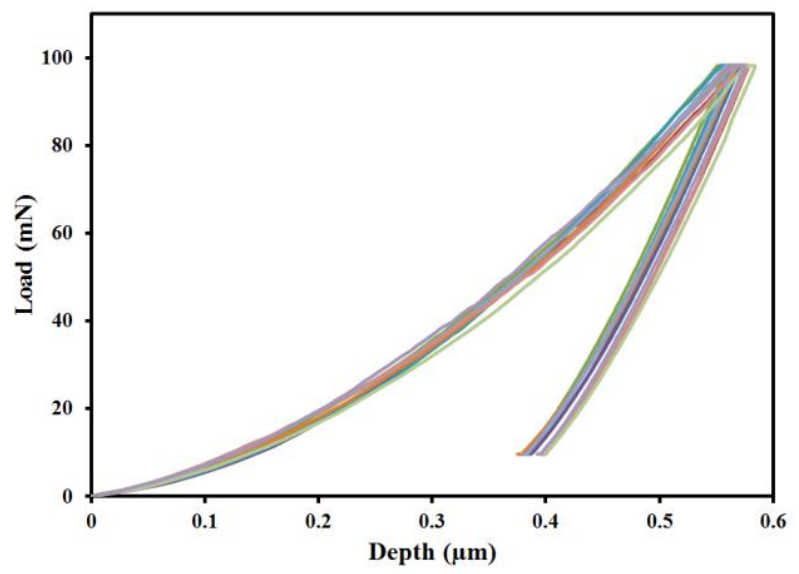

Figure 7 Load versus Depth profile determined for GDZS-50 from indentation. 


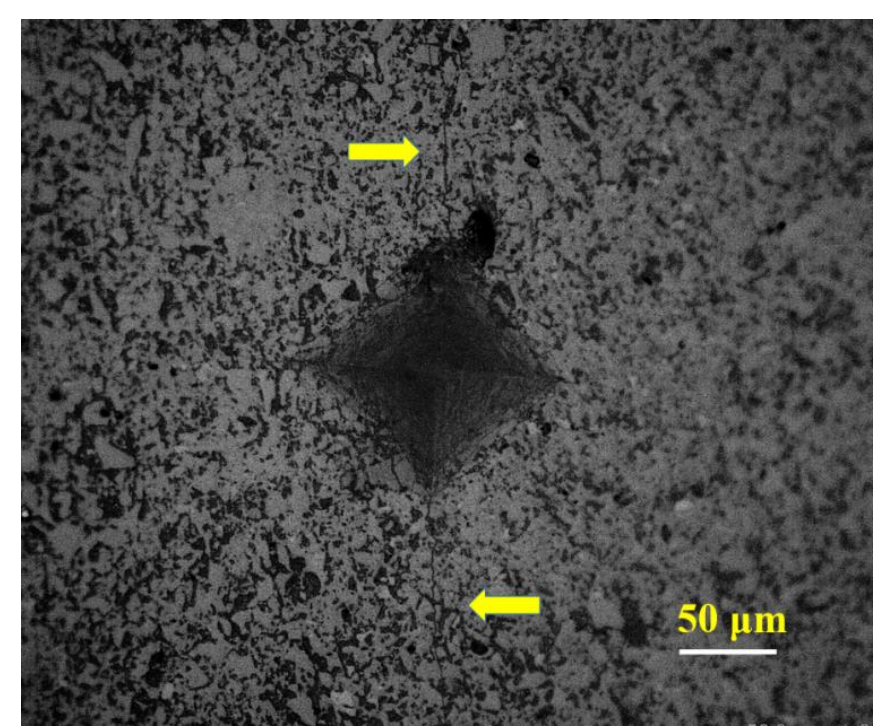

Figure 8 Optical micrograph of Vickers indentation on GDZS-50

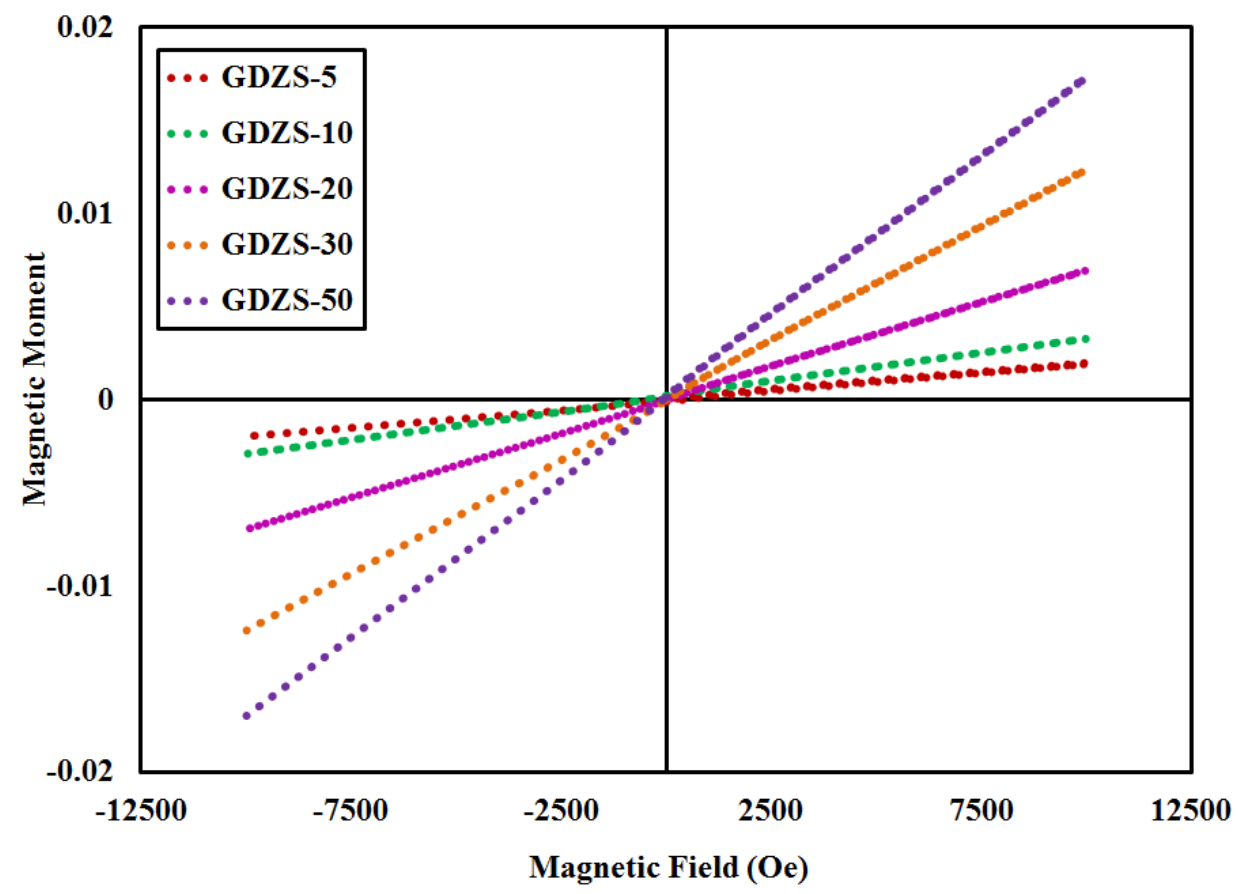

Figure 9 Hysteresis curves of $\mathrm{Gd}^{3+}$ and $\mathrm{Dy}^{3+}$ doped $\mathrm{ZrO}_{2}-\mathrm{SiO}_{2}$ binary oxides measured at room temperature. 


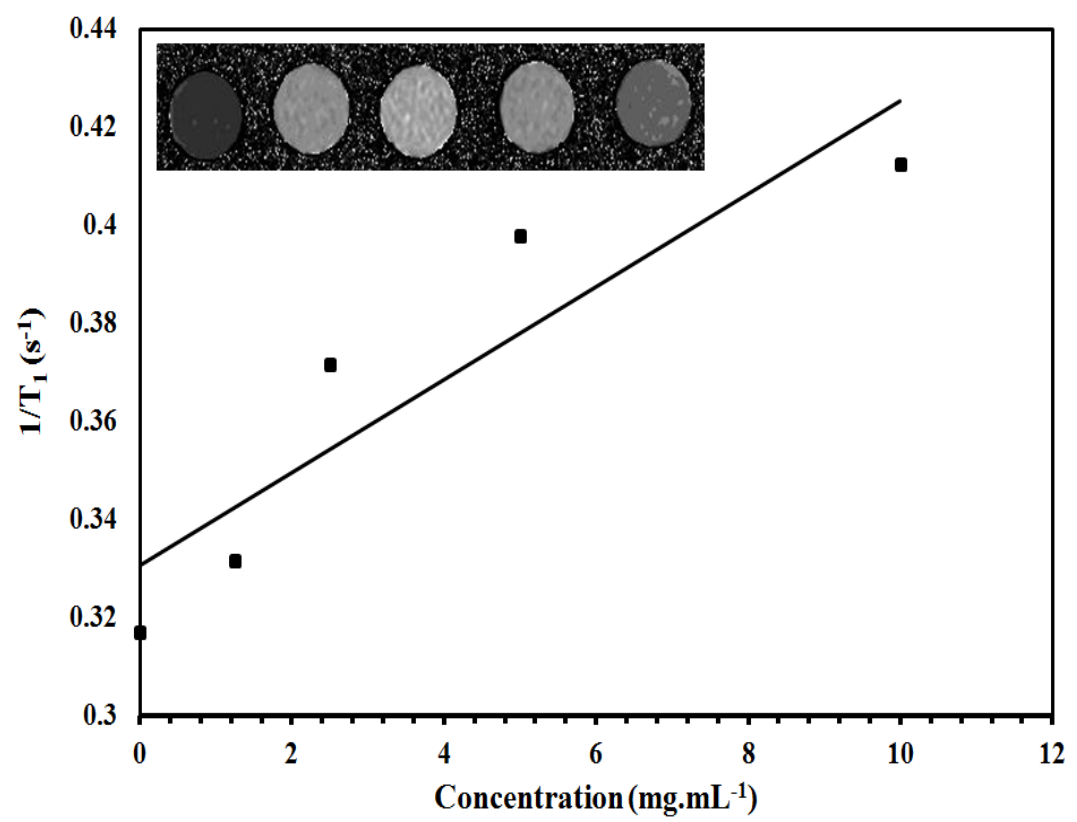

Figure $10 \quad T_{1}$ weighted MR images and relaxivity data of GDZS-50 with different concentrations.

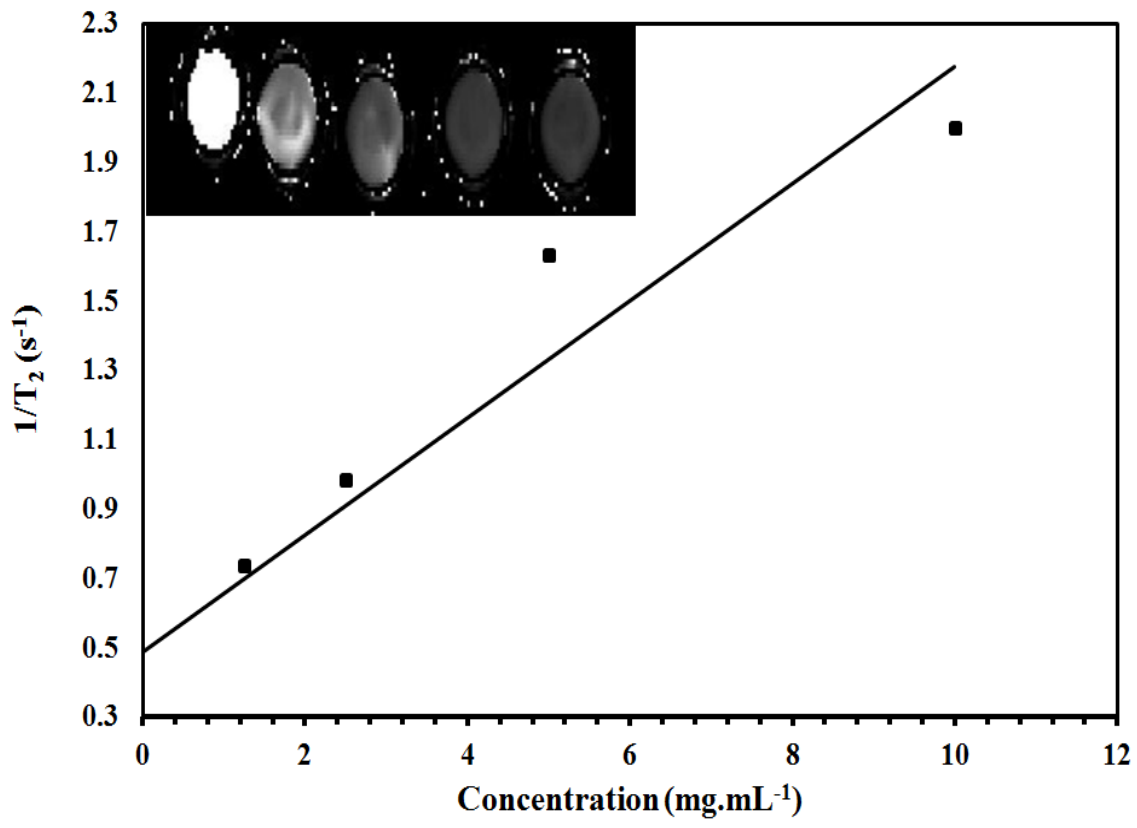

Figure $11 T_{2}$ weighted MR images and relaxivity data of GDZS-50 with different concentrations. 


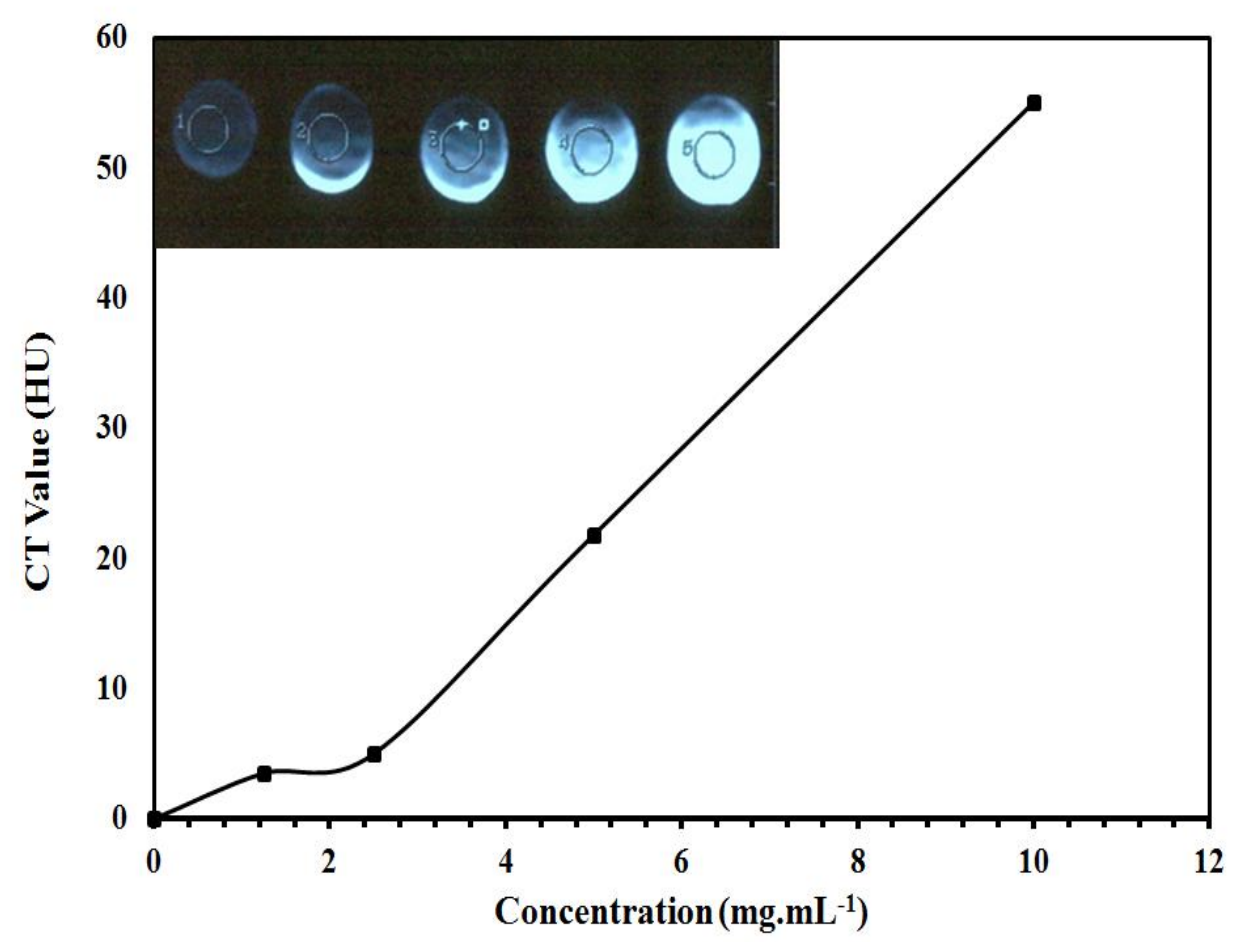

Figure 12 CT phantom images and CT data of GDZS-50 with different concentrations.

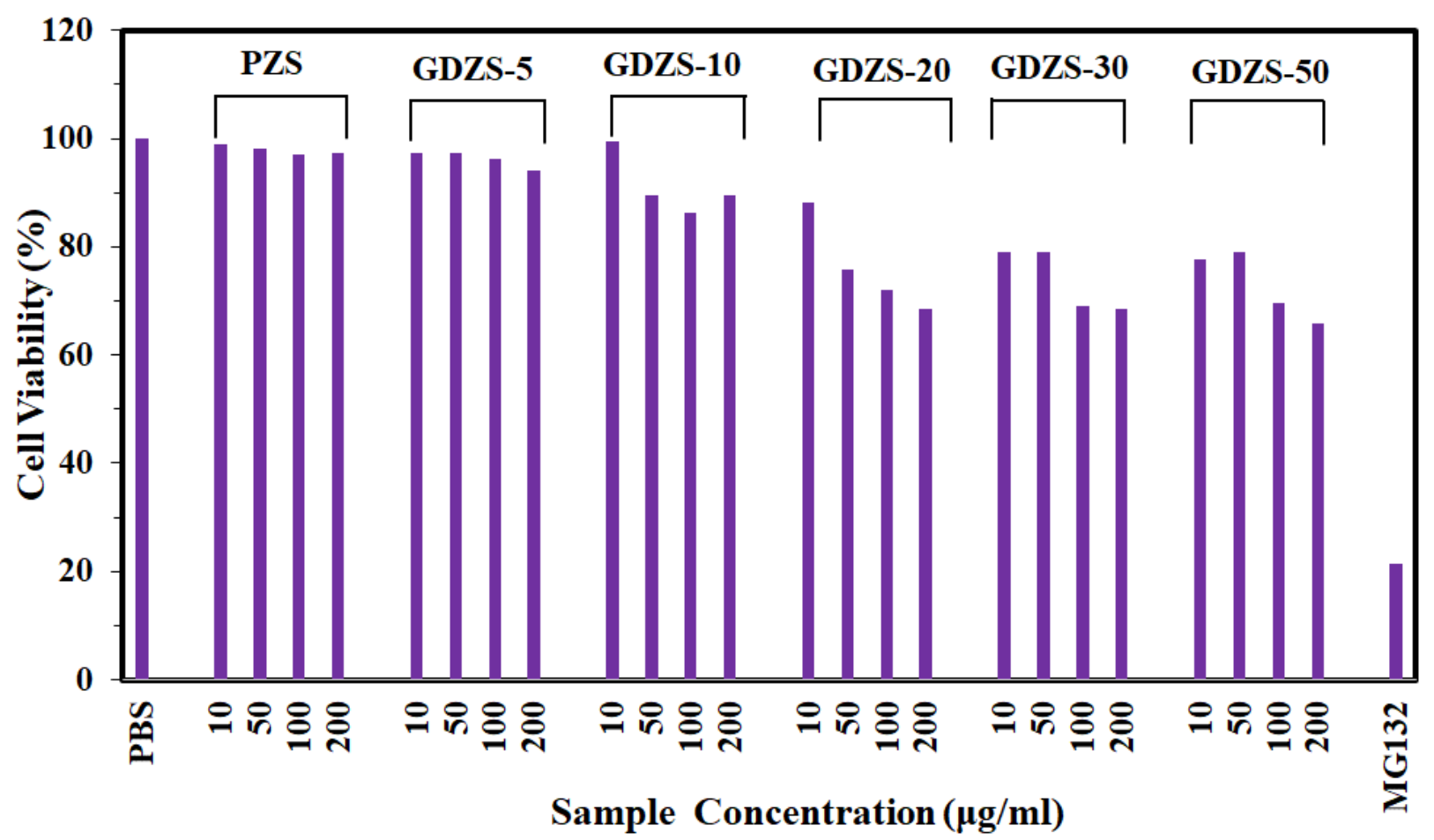

Figure 13

Percentage of viable MG-63 cells incubated with PZS and GDZS. 

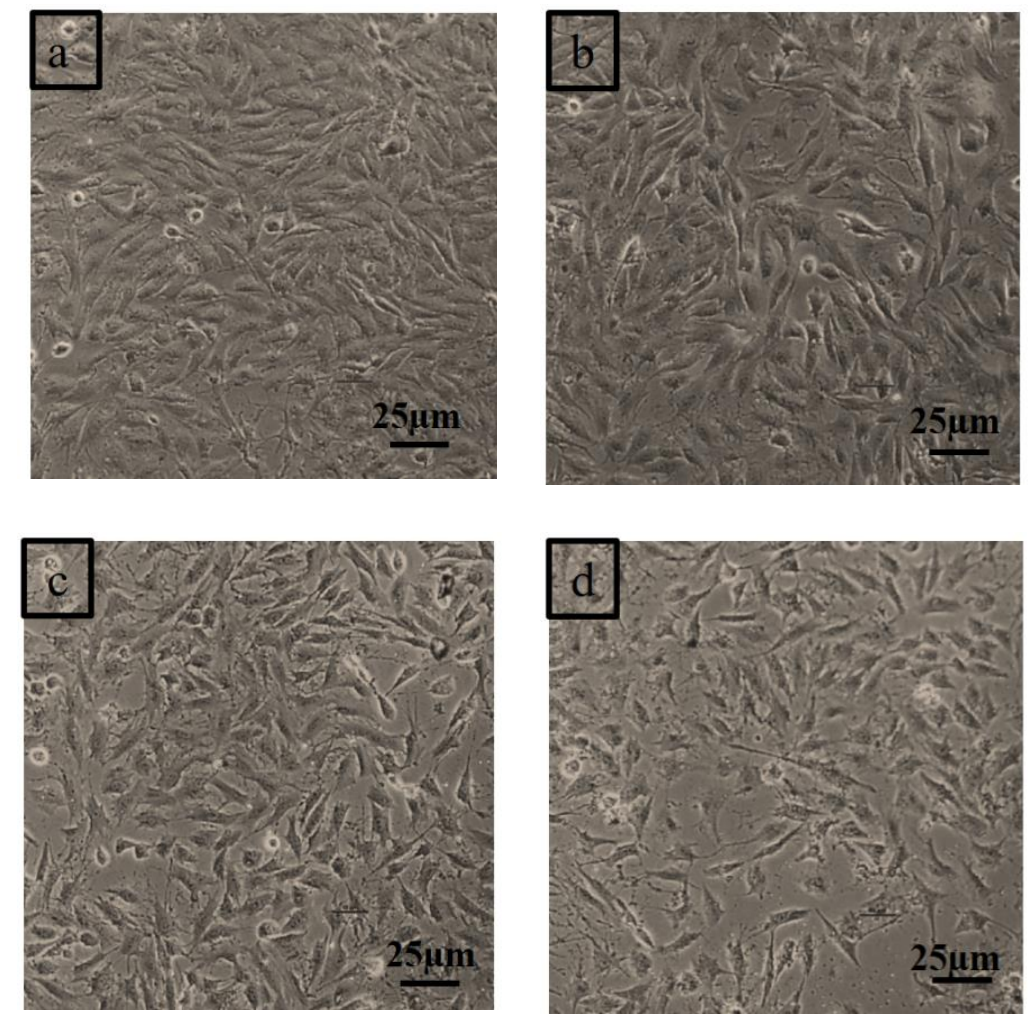

Figure 14

Optical microscopic images of MG-63 cells cultured with (a) PZS, (b) GDZS-10, (c) GDZS-30 and (d) GDZS-50. 

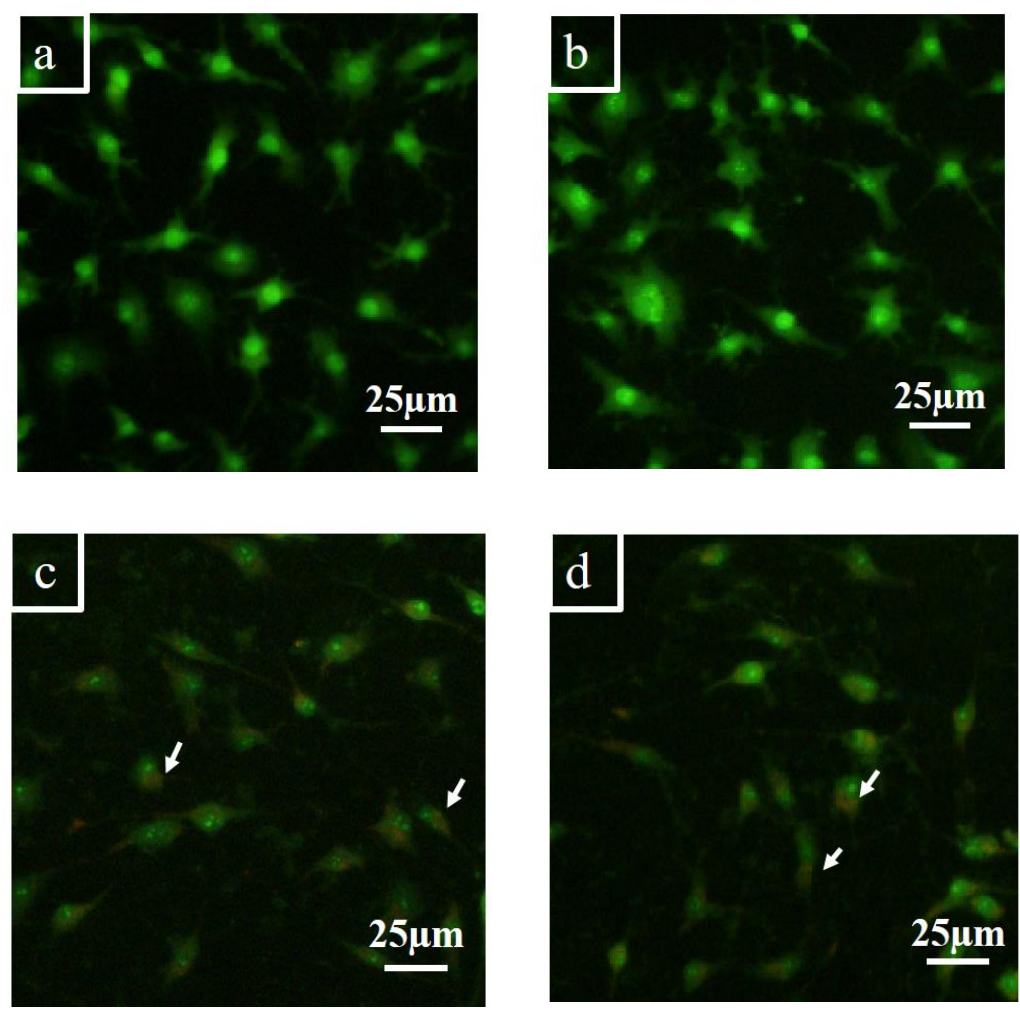

Figure 15

Fluorescence micrographs of live/dead dye-stained MG-63 cells incubated with PZS and GDZS. The representative cells which are stained red are indicated by arrow.

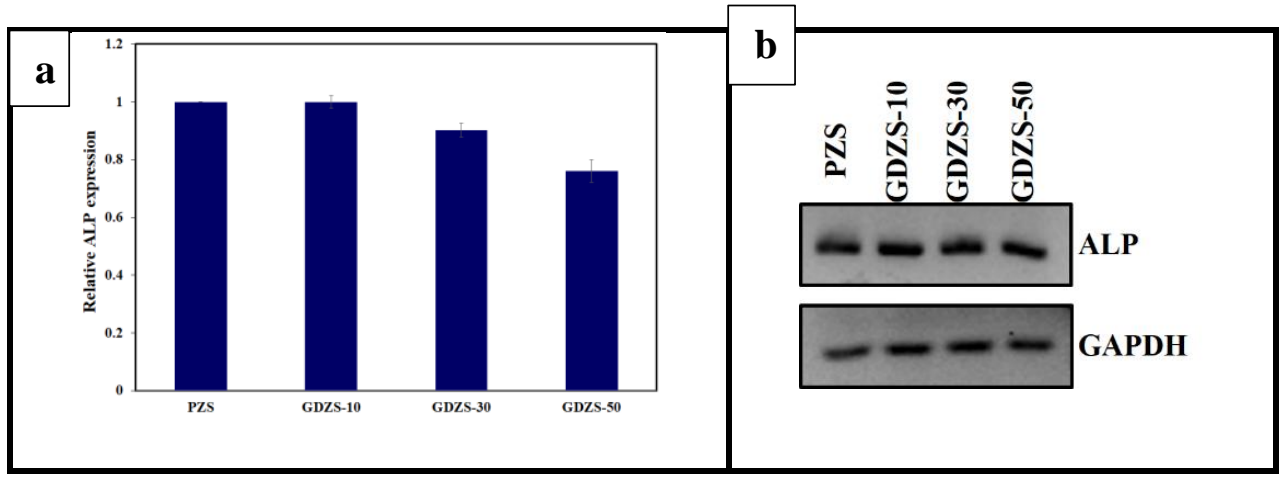

Figure 16

(a) Relative ALP expression in MG-63 cells as determined by qRT PCR upon the treatment with PZS and GDZS samples. (b) Agarose gel image of qRT-PCR products. 


\section{REFERENCES}

(1) Vasanthavel, S.; Nandhakumar, P.; Kannan, S. Quantitative analysis on the influence of $\mathrm{SiO}_{2}$ content on the phase behavior of $\mathrm{ZrO}_{2}$. J. Am. Ceram. Soc., 2014, 97, 635-642.

(2) Chavalier, J. What future for $\mathrm{ZrO}_{2}$ as a biomaterial. Biomater. 2006, 27, 534-543.

(3) Hench, L.L. Bioceramics. J. Am. Ceram. Soc. 1998, 81, 1705-1728.

(4) Monte, F. D.; Larsen, W.; Mackenzie, J. D. Stabilization of tetragonal $\mathrm{ZrO}_{2}$ in $\mathrm{ZrO}_{2}-\mathrm{SiO}_{2}$ binary oxides. J. Am. Ceram. Soc., 2000, 83,628-634.

(5) Vasanthavel, S.; Kannan, S. Development of Ageing Resistant and Bioactive $t-\mathrm{ZrO}_{2}$ Polymorph by the Combined Additions of $\mathrm{Ca}^{2+}, \mathrm{PO}_{4}{ }^{3-}$ and $\mathrm{SiO}_{2}$. J. Am. Ceram. Soc. 2016, $99(4), 1212-1220$.

(6) Wang, C., Zinkevich, M., Aldinger, F. Phase diagrams and thermodynamics of rare-earthdoped zirconia ceramics. Pure Appl. Chem. 2007, 79(10), 1731-1753.

(7) Doat, A.; Fanjul, M.; Pelle F.; Hollande, E.; Lebugle, A. Europium-doped bioapatite: a new photostable biological probe internalizable by human cells. Biomat. 2003, 24, 33653371.

(8) Ashokan, A.; Gowda, G. S.; Somasundaram, V. H.; Bhupathi, A.; Peethambaran, R.; Unni, A. K. K.; Palaniswamy, S.; Nair, S. V.; Koyakutty, M. Multifunctional calcium phosphate nano-contrast agent for combined nuclear, magnetic and near-infrared in vivo imaging. Biomat. 2013, 34, 7143-7157.

(9) Liu, M.; Liu, H.; Sun, S.; Li, X.; Zhou, Y.; Hou Z.; Lin, J. Multifunctional Hydroxyapatite/Na(Y/Gd)F $\mathrm{F}_{4}: \mathrm{Yb}^{3+}, \mathrm{Er}^{3+}$ Composite Fibers for Drug Delivery and Dual Modal Imaging. Langmuir. 2014, 30, 1176-1182.

(10) Ponnilavan, V.; Vasanthavel, S.; Singh, R. K.; Kannan, S. Influence of $\mathrm{La}^{3+}$ additions on the phase behaviour and antibacterial properties of $\mathrm{ZrO}_{2}-\mathrm{SiO}_{2}$ binary oxides. Ceram. Int . 2015, $41(6), 7632-7639$. 
(11) Behera, P. S.; Vasanthavel, S.; Ponnilavan V.; Kannan, S. J. Solid State Chem. 2015, 225, 305-309.

(12) Vasanthavel, S.; Derby, B.; Kannan, S. Stabilization of $t-\mathrm{ZrO}_{2}$ polymorph in glassy $\mathrm{SiO}_{2}$ matrix at elevated temperatures accomplished by Ceria additions. Dal. Trans. 2017, 46, 6884-6893.

(13) Vasanthavel, S; Derby, B.; Kannan, S. Tetragonal to Cubic Transformation of $\mathrm{SiO}_{2}$-Stabilized $\mathrm{ZrO}_{2}$ Polymorph through Dysprosium Substitutions. Inorg. Chem. 2017, $56,1273-1281$.

(14) Mi, P.; Cabral, H.; Kokuryo, D.; Rafi, M.; Terada, Y.; Aoki, I. Gd-DTPA-loaded polymermetal complex micelles with high relaxivity for MR cancer imaging. Biomat. 2013, 34, 492-500.

(15) Norek, M.; Peters, J. A. MRI contrast agents based on dysprosium or holmium”, Prog. Nuc. Mag. Res. Spec. 2011, 59, 64-82.

(16) Lee, N.; Choi, S. H.; Hyeon, T. Nano-sized CT contrast agents. Adv. Mater. 2013, 25 (19), 2641- 2660.

(17) Toby, B. H. EXPGUI: A Graphical User Interface for GSAS. J. Appl. Cryst. 2001, 34, 210-213.

(18) Smith, D. K.; Newkirk, H. W. The Crystal Structure of Baddeleyite (Monoclinic $\mathrm{ZrO}_{2}$ ) and its relation to the Polymorphism of $\mathrm{ZrO}_{2}$. Acta. Crystallogr. 1965, 18, 983-991.

(19) Howard, C. J.; Hill, R. J.; Reichert, B. E. Structures of the $\mathrm{ZrO}_{2}$ polymorphs at room temperature by high-resolution neutron powder diffraction. Acta Crystallogr., Sect. B: St. Sci. 1988, 44, 116-120.

(20) Wyckoff, R. W. G. Crystal Structures. John Wiley \& Sons, Inc, New York, 2nd edn. 1963, $239-444$

(21) Hazen, R. M.; Finger, L. W. Crystal structure and compressibility of Zircon at high pressure. Am. Mineral. 1979, 64, 196-201. 
(22) Dera, P.; Lazarz, J. D.; Prakapenka, V. B.; Barkley, M.; Downs, R. T. New insights into the high-pressure polymorphism of $\mathrm{SiO}_{2}$ cristobalite. Phys. Chem. Miner. 2011, 38, $517-529$.

(23) ISO. ISO 14577. Metallic Materials-Instrumented indentation test for hardness and materials parameters. ISO, 2002.

(24) Veljovic, D.; Palcevskis, E.; Zalite, I.; Petrovic, R.; Janackovic, D. Two-step microwave sintering-A promising technique for the processing of nanostructured bioceramics. Mater. Lett. 2013, 93, 251-253.

(25) Evans, A. G.; Charles, E. A. Fracture Toughness Determinations by Indentation. J. Am. Ceram. Soc. 1976, 59, 371-372.

(26) Vasanthavel, S.; Kannan, S. Phase stabilization of $\mathrm{ZrO}_{2}$ polymorph by combined additions of $\mathrm{Ca}^{2+}$ and $\mathrm{PO}_{4}{ }^{3-}$ ions through in-situ synthetic approach. J. Amer. Ceram. Soc., 2014, 97, 3774-3780.

(27) Phillippi, C. M.; Mazdiyasni, K. S. Infrared and Raman Spectra of Zirconia Polymorphs. J. Am. Ceram. Soc. 1971, 54 (4), 254-258.

(28) Itoh, T. Formation of poly crystalline zircon $\left(\mathrm{ZrSiO}_{4}\right)$ from amorphous silica and amorphous zirconia. J. Crys. Growth. 1992, 125, 223-228.

(29) Arcos, D.; Regí, M. V. Sol-gel silica-based biomaterials and bone tissue regeneration. Acta. Biomat. 2010, 6, 2874-2888.

(30) Wang, S. W.; Huang, X. X.; Guo, J. K. Mechanical properties and microstructure of $\mathrm{ZrO}_{2-}$ $\mathrm{SiO}_{2}$ composite. J. Mat. Sci. 1997, 32, 197-201.

(31) Tekeli, S.; Boyacıglu, T.; Gural, A. The effect of silica doping on the microstructure and mechanical properties of $c-\mathrm{ZrO}_{2} / \mathrm{SiO}_{2}$ composites. Ceram. Int. 2008, 34, 1959-1964.

(32) Piconi, C.; Maccauro, G. Zirconia as a ceramic biomaterial. Biomat. 1999, 20, 1-25. 
(33) Kurtz, S. M.; Kocagöz, S.; Arnholt, C.; Huet, R.; Ueno, M.; Walter, W. L. Advances in zirconia toughened alumina biomaterials for total joint replacement. J. Mech. Behav. Biomed. Mat. 2014, 31, 107-116.

(34) Mangalaraja, R. V.; Chandrasekhar, B. K.; Manohar, P. Effect of ceria on the physical, mechanical and thermal properties of yttria stabilized zirconia toughened alumina. Mat. Sci. Eng. A, 2003, 343, 71-75. 
For "Table of Contents" use only

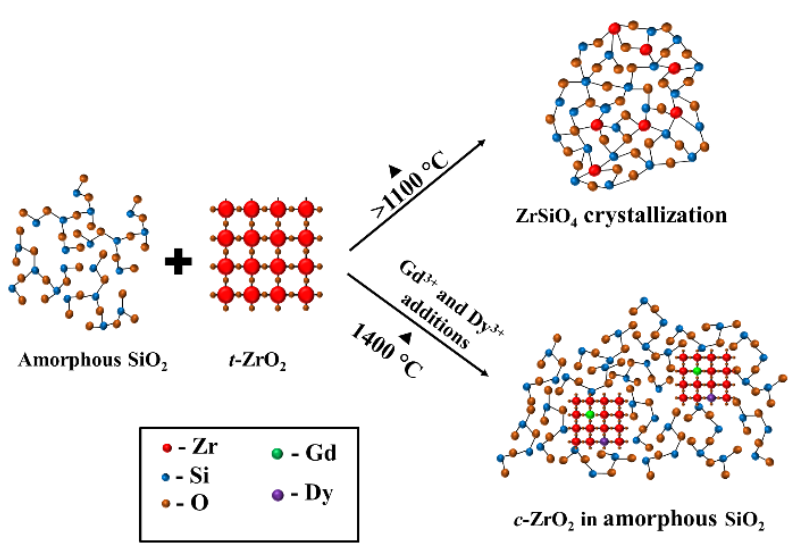

$\mathrm{Gd}^{3+}$ and $\mathrm{Dy}^{3+}$ combination in $\mathrm{ZrO}_{2}-\mathrm{SiO}_{2}$ binary system delays the crystallization of $\mathrm{ZrSiO}_{4}$ and stabilizes $c-\mathrm{ZrO}_{2}$ in amorphous $\mathrm{SiO}_{2}$ matrix 